\title{
Semantic Features in Argument Selection
}

\author{
Izchak M. Schlesinger \\ Hebrew University, Jerusalem, Israel \\ Email: msizchak@mscc.huji.ac.il \\ Received February $27^{\text {th }}, 2013$; revised April $2^{\text {nd }}, 2013$; accepted April $9^{\text {th }}, 2013$
}

\begin{abstract}
Copyright (C) 2013 Izchak M. Schlesinger. This is an open access article distributed under the Creative Commons Attribution License, which permits unrestricted use, distribution, and reproduction in any medium, provided the original work is properly cited.
\end{abstract}

\begin{abstract}
One of the problems that has to be dealt with by theorists of early language acquisition theory is the mismatch between semantic constructs, like Agent, and syntactic ones, like subject. It is proposed that the linguistic system is based on semantic features that are more fine-grained than thematic roles, and that selection of subject and direct object can be accounted for by merely four semantic features. These features are conceived of as properties of participants in the lexical entries of verbs, and in this respect, too, they are unlike thematic roles, which are ascribed to NPs in sentences. Thematic roles play a part only in the realization of certain other arguments, notably, the oblique object. It is shown that this different treatment of direct and oblique objects permits a parsimonious explanation of certain linguistic regularities that have posed problems for other theories. Early language acquisition can be explained in terms of the acquisition of these semantic features, and this account thus supersedes the semantic assimilation hypothesis proposed previously to deal with the lack of congruence between thematic roles and syntactic categories.
\end{abstract}

Keywords: Semantic Features; Thematic Roles; Linking Rules; Language Acquisition

\section{Introduction}

Several theories of argument selection have followed Fillmore's (1968) seminal paper and dealt with the semantic-syntactic interface in terms of what have been variously called thematic relations, thematic roles, or $\theta$-roles. The construct of thematic roles and that of a thematic role hierarchy have come under criticism from various quarters (e.g., Davis \& Koenig, 2000; Dowty, 1989, 1991; Gropen et al., 1991a; Hoekstra, 1992; Levin \& Rappaport Hovav, 2005; Newmeyer, 2002; Schlesinger, 1995: pp. 28-29; Zubizaretta, 1987, among others). As Andrews (2007: p. 140) observes, “... no presently known system of semantic roles can be applied in a comprehensive and convincing manner"1. Instead of thematic roles, Van Valin (2005) therefore posits more global "macro-roles". Some other theorists propose less global notions, such as semantic features (see, e.g., McRae et al., 1997; Zubizaretta, 1987). In Jackendoff's (1987: p. 409) system, thematic roles are derived notions "argument positions in conceptual structure" that are constituted of more basic semantic concepts which are akin to features. Others view features as elements into which thematic roles are decomposed (Rozwadowska, 1988), as "entailments" characterizing "protoagent" and "proto-patient" roles (Dowty, 1991), or as occupying a level preceding that of thematic roles (Schlesinger, 1995).

In the present paper it is argued that realization of the subject and the direct object can be accounted for without resorting to thematic hierarchies or to conceptual structures like those proposed by, e.g., Jackendoff (1990b) and Kiparsky (2001). Instead, rules defined over certain semantic features are formu-

\footnotetext{
${ }^{1}$ And Chomsky (1982: p. 89) once remarked in an interview: "I never know how people are able to pick out thematic relations with such security, I can't'.
}

lated, which link NPs to the subject and the direct object. Thematic roles are conceived of as playing a part only in the realization of certain other arguments. This theory affords a more parsimonious explanation of linguistic phenomena and solves certain problems encountered by a theory of early language acquisition ${ }^{2}$.

The first section of this paper introduces the semantic features figuring in the present system. Then a theory is developed in which features residing in the lexical entries of verbs determine the selection of subject and direct object. Certain linguistic regularities are accounted for by assuming that the realization of oblique objects differs in that it involves thematic roles. The final section shows how the language learning child can acquire such a feature-based grammar.

\section{Features of Subjects}

The purpose of this section is to introduce the features that function in my system. Examples will be given of features that characterize subjects, but some of these features appear not only in subjects. The linking rules that select subjects and direct objects will be discussed in the section on "Selection of subjects and objects".

\section{Cause}

The subjects of the following sentences pertain each to the cause of the activity referred to by the verbs:

\footnotetext{
${ }^{2}$ The present theory is an extensive modification of some ideas first expounded in Schlesinger (1995). Among others, the system of features has been much simplified, the hypothesized level of "cases" mediating between features and syntactic structures has been abandoned. Some criticisms of that book by Rosta (2002) have also been taken into account.
} 
1) a. Sybil drank her coffee.

b. Ron pushed Jack.

c. My uncle refused the offer.

d. Sheila is swimming.

e. The girl cried.

f. Bill was snoring on the couch.

Each sentence in 1) describes an activity caused by the entity referred to by the subject, and so the feature Cause is accorded to each of the subjects (or, more precisely, to the elements in the lexical entries of the respective verbs that are linked to the subjects. Cause characterizes internal causation, as in 1d), 1e), and $1 \mathrm{f}$ ), as well as agents causing a change in another entity ${ }^{3}$.

\section{Control}

The animate subjects in 1) are not only the cause of the activity referred to, but also have Control over it (see Siewierska 1991: 47-49 on this feature). Our feature Control differs somewhat from Dowty's (1991) entailment "volitional", as is shown by the following examples:

2) a. Celia refrained from interfering.

b. Ronald is sleeping in his armchair.

c. Our community tolerates eccentric behavior.

d. My aunt underwent surgery.

Celia is in control in so far as she can desist from refraining (that is, she can start to interfere), and one probably can, at least in some cases, voluntarily stop sleeping, and decide to behave intolerantly. And the lady referred to in $2 \mathrm{~d}$ ) by my aunt may refuse to be operated on or escape from the hospital.

Cause and Control are closely related features; they differ mainly in the phases of the activity which they focus on. Stated roughly, Cause initiates the activity and Control steers it or even terminates it. In fact, Cause and Control usually go together. Most of the subjects in 2) have also the feature Cause. Refraining is "caused" by Celia, just as crying in 1e) is caused by the girl. An exception is 2d): the lady does not cause anything (surgery is performed by surgeons), but she may be said to be in control. There are also subjects that have only Cause and no Control, as for instance the subject of snore; see 1f).

\section{Change of State or Location}

When a NP refers to an animate or inanimate entity undergoing a change of state, we will say that it has the feature Change.

3) a. The ice will melt.

b. Their son has grown up.

c. The hamster died in his cage.

d. The rainbow slowly vanished.

e. The waiter slipped on the wet floor.

The ice, their son, and the hamster are said to undergo a change of state, the rainbow and the waiter, a change of location $^{4}$.

Some of the verbs in 1) also involve movement in addition to

\footnotetext{
${ }^{3}$ These distinctions between kinds of causes, as well as those proposed in Schlesinger (1995), are not needed for the purpose of accounting for subject and object selection. The subjects in 1) seem to be close to what Van Valin and Wilkins (1996) call "effectors" and Levin and Rappaport Hovav (1995: p. 135) call "immediate causes".

${ }^{4}$ The set of verbs having subjects with the feature Change overlaps more or less with that of unaccusative verbs.

${ }^{5}$ Phrasal predicates, like that in $4 \mathrm{~h}$ ) will not be further discussed in the present paper.
}

Cause. Further on, I discuss the question of whether they have the feature Change.

\section{Attributee of State}

Some verbs, like those in 4), refer to states or to properties that are attributed to the subject ${ }^{5}$.

4) a. This box contains small coins.

b. This car needs an overhaul.

c. Smith is a pauper.

d. You really deserve a special treat!

e. The organization lacks funds for rebuilding.

f. Ken likes ice cream.

g. She fears him.

$\mathrm{h}$. He has a mole on his right shoulder.

I propose to introduce a feature that has not been discussed in the literature, to my knowledge: attributee of a state or property, or Attr-St, for short. There is no cause-and-effect relationship between the subjects and predicates of these sentences. One does not conceive of the box as being the cause of containing anything or of the car as causing its needing anything; instead, containing and needing are states or properties attributed to them ${ }^{6}$.

Examples 4f) and 4g) are of so-called mental verbs (or "psych-verbs") in which the experiencers are sentence subjects. The subjects of these and other such verbs admire, respect, pity, hate, loathe, and dread, among others have the feature Attr-St. Some mental verbs can appear in the imperative form, as in 5). Presumably this is because one may have some degree of control over one's emotions, which suggests that these verbs have also the feature Control ${ }^{7}$.

5) a. Don't pity me!

b. Don't hate your enemy!

Conversely, the subjects in 2a), 2b), and 2c) should be assigned the feature Attr-St in addition to Control, because the verbs attribute properties to their subjects.

The subjects of verbs denoting posture, like those in 6), may be viewed as having several features.

6) Herb is sitting/lying on the couch.

Usually, sitting and lying result from one's deliberately assuming a posture, and one can also desist from assuming it (or determine one's manner of doing so). Subjects of the verbs sit and lie thus have the features Cause and Control, in addition to Attr-St, and so have some other stative verbs, like stand, and lean ${ }^{8}$.

There are also some unclear cases. For instance, does the subject of find have the feature Cause (i.e., is finding an activity, like seeking) or Attr-St? One should not assume the existence of a sharp boundary line between these two features.

\section{On the Nature of Features}

Three classes of verbs have been described here: activity verbs, the subjects of which have Cause and/or Control, process verbs, and state verbs, the subjects of which have Change and Attr-St, respectively. Not included in our list of features are

\footnotetext{
${ }^{6}$ The direct objects in these sentences (or in any sentence, for that matter) do not have this feature. Nothing is expressly attributed to small coins in (4a); one can only infer that they are in the box.

${ }^{7}$ In a rating study (Schlesinger, 1992), it has been shown that adult speakers judge subjects of these verbs to have a greater degree of control than their direct objects.

${ }^{8}$ These verbs may be also be predicated of inanimate subjects by a kind of metaphorical extension. See section on NP matching for the mechanism that operates here.
} 
some of those found in the literature, like animacy and sentience ${ }^{9}$. These and some other features can possibly account for some linguistic phenomena that are not explainable in terms of the above four features, but they are not needed for stating the linking rules that select subjects and direct objects. In the following, this will be shown to be true for English. Not only languages that do not have subjects (like Tagalog, which has a predicate-topic structure; Schachter \& Otanes, 1972), but also other languages with a subject-predicate structure may require additional features (see, e.g., Hopper \& Thompson, 1980).

The theory proposed in the following sections is more parsimonious than theories based on thematic hierarchies, and accordingly the difficulty of learning the basic linking rules of the native language is diminished, as shown in the last section. It might be argued that the foregoing four features are thematic roles in disguise. Note the considerable overlap of features Cause and Control with Agent, of Change with Theme or Patient, and of Attr-St with Experiencer. However, unlike thematic roles, features are relatively unequivocal and easily identified. To decide whether something undergoes a change is simpler than deciding whether it is a Theme. This is partly due to there being a larger number of thematic roles than of the features proposed here; the latter are more basic concepts, each of which may be common to a number of roles. Further, while definitions of thematic roles are typically vague, and as a result cannot be applied easily "outside classes of the verbs which have been used to motivate the $\theta$-roles or are extended in unprincipled ways to new cases" (Rappaport \& Levin, 1988: p. 8), this will be seen not to be true of features.

Another basic difference between thematic roles and our features is that while the former are usually conceived of as appertaining to NPs, features are characteristics of participants in the lexical entries of verbs, as will be seen in the next section.

\section{The Linking Problem}

In the next section it will be shown how linking rules for subject and direct object can be formulated in terms of the four features discussed in the foregoing: Cause, Control, Change, and Attr-St. In the present section, I show that - unlike the rules in current theories, which are defined in terms of characteristics of the NPs - the rules that select the subject and direct object can be defined on features of lexical entries of verbs. But first, some of the concepts figuring in the present theory will be explained.

\section{Lexical Entries}

\section{Participants and Features}

Consider two simple sentences:

7) a. Doris broke the window pane.

b. Dan spilled the wine.

The subjects and direct objects of these sentences are determined by the lexical entries of the verbs break and spill, respectively. Every lexical entry of a verb contains a "scene". The scene for break, for instance, is a mental representation of breaking, and it includes mental representations for each of the

\footnotetext{
$\overline{{ }^{9} \text { McRae et al. (1997) propose "features" which, unlike our features, are close }}$ to what Dowty (1989: pp. 76-77) calls "individual thematic roles", i.e. verbspecific (though each may characterize a large proportion of verbs in the language).

${ }^{10}$ Note that "scene" is used here for the mental representation of a verb, and not in the sense used by Fillmore (2003: pp. 209-213).
}

participants in the breaking activity, namely, the one who breaks and the object that is broken ${ }^{10}$.

It is important to bear in mind that in the present system the term "participant" does not refer to arguments, like subject and object (as Hopper and Thompson 1980, for instance, use this term). Neither does it refer to NPs or to their referents: instead, NPs are mapped into participants, as will be shown below.

There are many kinds of breaking: one can break chairs, pencils, windows, threads, etc. Therefore the mental representation of the action of breaking must be schematic (just as dictionary definitions ought to be sufficiently abstract to accommodate most instances of the defined term). The participants included in the mental representation will also be schematic: there are not only several ways of breaking but also kinds of breakers and of things that can be broken.

Each participant has certain syntactically relevant features. The following examples illustrate formulas for lexical entries (the left-to-right sequence of the participants being a matter of convenience and having no theoretical significance whatsoever):

break: "breaker" (Cause, Control), the thing broken (Change) spill: "spiller" (Cause, Control), the material spilled (Change)

No further decomposition of predicate verbs is needed for subject and object selection. The linking rules selecting subjects and direct objects are defined for features of the participants in the lexical entry and will be called feature linking rules. One such rule determines that the feature Cause is linked to the subject and another one that the feature Change may be linked to the direct object; see the next section for a discussion of feature linking rules.

The participant in a lexical entry which, after the appropriate feature linking rules have applied, corresponds to the subject (in active sentences) e.g., the "breaker" and the "spiller" will be called here subject participant. Similarly, the participant that ends up as direct object (the thing broken, the material spilled) will be called the object participant. These terms are merely convenient labels; the participants themselves have neither subject nor object character prior to the application of feature linking rules.

An assumption made by the present theory is that a lexical entry of a verb can include at most two participants: the subject participant and the object participant. Oblique objects are not realizations of participants but rather are arrived at by a different kind of linking rules; the rationale for this will be discussed in the section on Roles of NPs (below). Transitive sentences contain two participants, each of which may be realized by one $\mathrm{NP}$, as in 7), or by more than one, as in 8):

8) Jim and John broke the vase, the saucers, and the salt shaker.

The lexical entries of intransitive verbs contain only one participant, which will be realized as subject, e.g.,

cry: the one who cries (Cause, Control)

melt: the material that melts (Change)

Verbs that have a subject participant with the feature Change, like cry and melt, are usually intransitive, but there are some exceptions, e.g.,

9) The pensioner sustained an injury.

sustain: affected entity (Change), source of affecting (ø)

Here the object participant does not have any one of the features introduced so far-Cause, Control, Change, and Attr-St. The symbol $\varnothing$ - the "default feature"- stands for the absence of 
any one of these features ${ }^{11}$.

Lexical entries of verbs that have expletive subjects (like rain) have no featured participants.

\section{Assigning Features}

A comment is in order regarding the feature Change. This feature is broadly conceived in the present system. Both affected and effected objects have Change:

10) a. David damaged this machine.

b. David constructed this machine.

Change may stand for change of state, as in the object participant in 10a), or for change of location, i.e. motion, as in the object participant of spill. There are also mental changes (as in the direct objects of frighten, and surprise), changes of status (as in the direct objects of elect, nominate, appoint, promote, convict, indict). Further, as illustrated in 10b), Change may apply to entities which come into being as a result of the activity referred to by the verb, and these may also be abstract entities (cf. pass a resolution, devise a strategy, deliver a lecture). Changes can be scalar (as in mature or learn) or non-scalar (as in break or laugh). All these distinctions do not appear to be linguistically relevant as far as subject and object selection go, and will be ignored in this paper.

In the case of many verbs it is not immediately clear whether their lexical entries contain a given feature. For example, the subject participants of many verbs involve a limited degree of movement in addition to Cause and/or Control. To break something, one moves one's arms (or legs) and spilling is normally accompanied by some motion. The feature Change characterizes the subject participants of only those verbs that refer to activities in which movement or a change of state are essentially involved, such as swim, run, walk, enter, jump, and not of verbs like break, spill, or drink, where the movement or change of state are incidental. Movement is not part of the meaning of the actor of break, spill, and drink, whereas in the case of swim, run, and walk, change of location is part of the meaning. The statement He ran without moving is an oxymoron (the first part of the sentence contradicts the second one), but He drank wine without making the slightest movement describes, at most, a physical impossibility. I propose this here as a rule of thumb, but naturally there will be many unclear cases.

Similarly, Change is assigned to an object participant only when there is an "essential" change in it. For instance, the object participant of break has, but that of hit does not have the feature Change. This is because 11a) is self-contradictory due to the meaning of break, which involves a change in the object broken, whereas 11b) asserts what is perhaps a physical impossibility, but the sentence is not self-contradictory.

11) a. *Doris broke the window pane, but it remained intact. b. Doris hit the TV screen, but it remained intact.

There will of course be borderline cases, namely verbs where it is hard to decide whether the change (in either the subject or the object participant) is essential or not, but as should become clear further on, this will not affect the application of linking rules $^{12}$

Some verbs may refer to events that either do or do not in-

\footnotetext{
$\overline{{ }^{11} \text { Cf. Fillmore's (1968) "Objective", which is a catch-all case. Some writers }}$ use "Theme" in a similar manner.

${ }^{12}$ In a lexical entry formula, I will sometimes leave out Change, even where a good case can be made for including it. In most instances, adding Change to features of the subject participant will not make any difference to linking, as will become clear in the section on subject selection.
}

volve a certain feature. For instance, a person who is lying on some surface is obviously in a state, and so the subject participant of lie has Attr-St; cf. example 6). But against the claim made there that lie also has the features Cause and Control, one might want to argue that an unconscious person, for instance, may be put on a stretcher or on a bed (and so does not cause anything) and left to lie there (without having any control over the situation). A related problem, which will be dealt with further on, may arise with verbs that may take either animate or inanimate subjects. However such objections overlook the fact that features are assigned to lexical entries and not to verbs in particular contexts ${ }^{13}$. The lexical entry of a verb is determined by its standard use, and the verb lie, as used standardly, has subjects referring to the person or animal that is the (internal) cause of assuming this posture and is in control of it.

There will be verbs which may raise doubts as to their standard use. Fortunately, this will normally not be problematic for subject selection, as will be seen from the formulation of the subject linking rule further on.

\section{Features Are Independent of Context}

Features of participants reflect the meaning of the verb, and this means that they are independent of the sentence in which the verb appears. This is an important point that is easy to overlook, as the following examples show.

12) a. The police suspected the pickpocket.

b. The police accused the pickpocket.

Suspect is a mental verb, and its subject participant has the feature Attr-St; cf. 4f) and 4g). Accuse has a subject participant with Cause and Control. In both 12a) and 12b), the police is therefore the subject. But what about the pickpocket? Plying his trade led to his being suspected or accused, and so one might maintain that the pickpocket caused the event referred to by the verb (and if so, the pickpocket competes with the police for subject position). A similar question might arise also with many other verbs, like blame, praise, arrest, punish, and reward.

But this argument is based on a faulty assumption. Lexical entries are not determined by the context in which the verb appears. It is not NPs or their referents that have the feature Cause, but participants in the lexical entry. Sentences like 13) show that the meaning of suspect or accuse does not imply that the person suspected or accused is necessarily the cause of what the verb refers to.

13) a. The police suspected an innocent bystander.

b. The police accused an innocent bystander.

Each of the lexical entries of suspect and accuse therefore includes one participant eligible for subject position and another participant with the "default feature", and so have the lexical entries of blame, praise, arrest, punish, and reward.

suspect: "suspecter" (Attr-St), "suspectee" (Ø)

accuse: "accuser" (Cause, Control), "accusee" (ø)

It is important therefore to keep in mind that features are context-free. In this respect, thematic roles are usually conceived of differently; they are "components of the mental representation of objects and concepts" (Wilkins, 1988: p. 191), and not components of the meaning of verbs, like features. As a result, truth-conditionally equivalent sentences have identical

\footnotetext{
${ }^{13}$ Although it is the participants in lexical entries, and not NPs that have features, it will be convenient to use the somewhat imprecise expression that "the NP... has the feature $F$ ", which should be taken to mean "the participant which is realized as the NP... has the features $F$ ". Occasionally I will write "the subject/direct object has the feature $F$ ".
} 
role assignments. On this view, assignment of a thematic role may depend on the sentential context. Thus, when the sentence states that an activity was performed accidentally, the actor may be assigned a thematic role that differs from that of a sentence which states that the activity was performed for some purpose.

The assumption that thematic roles are sensitive to the part played by a NP in the situation described may give rise to problems. For instance, Grimshaw (1990: pp. 19-21) discusses two sentences describing the same situation:

14) a. The storm frightened us.

b. We feared the storm.

Assuming Baker's (1988: p. 37) theta criterion, Grimshaw argues as follows. The storm is Theme in both sentences, since the sentences are near-paraphrases of each other. Likewise, we $(u s)$ is Experiencer in both. Since Experiencer precedes Theme in the thematic hierarchy, an explanation is required for the fact that in 14a) the storm, the Theme of frighten, is subject. Grimshaw thus focuses on the situations described by the NPs in these sentences, rather than on the verbs. Her reasoning is based on the assumption that if a NP has the thematic role $R$ in a given sentence $S$, it must have the same role in every sentence that paraphrases $S$, or as Dowty (1991: 563) writes: “... any truthconditionally equivalent sentence has the same role assignments".

In a section the heading of which is called, appropriately, "The inadequacy of thematic reanalysis", Grimshaw accounts for the fact that subject selection in 14a) does not conform to the hierarchy of thematic roles, by stating that the storm has causal status, which is why it can be subject ${ }^{14}$. According to her analysis, then, thematic roles cannot do the job by themselves; the feature Cause comes in through the back door. Further on, it will be shown how 14) is dealt with in the framework of the present theory.

\section{NP Matching}

In the present system, then, features are attributes of participants in lexical entries, not of NPs. NPs may match participants in the lexical entry of a verb. For the purpose of a schematic illustration that does not pretend to mirror actual performance of language users, let us assume that a speaker intends to state that Doris has broken a window pane. Expressing this idea involves choosing a verb that describes the activity, and break fills this bill ${ }^{15}$. The lexical entry of this verb is break: "breaker" (Cause, Control), thing broken (Change).

This lexical entry prescribes that two NPs pertinent to the event be selected, one for each participant, the "breaker" and the "thing broken". Doris can be matched with the "breaker" and the window pane, with the "thing broken". The Feature linking rules to be formulated further on, link Doris to the subject and the window pane to the direct object. The resulting sentence is

15) Doris broke the window pane.

\footnotetext{
${ }^{14} \mathrm{~A}$ different solution to this problem has been proposed by Belletti and Rizzi (1988).

${ }^{15}$ In some cases, the NP determines the choice of the verb. In sentences like have fun, make an effort, give evidence, the effected objects incorporate most of the meaning in the verb phrase and the "light" verbs have, make, and give make only a subsidiary contribution to the meaning. The nouns that serve as effected objects of these verbs are usually not deverbal: fun, effort, and evidence do not have corresponding verbs (*to fun, *to effort, *to evidence). Even when a corresponding verb exists, it will have a slight difference of meaning. Thus, the baby can have a bath, but hardly bathe, and when someone gives a talk he (hopefully) does more than just talking.
}

\section{Matching May Ignore Features}

Usually a NP matches a participant not only in respect to its general sense, but also in respect to the participant's features. In 15), Doris corresponds closely to the "breaker" participant of break, because Doris is the cause of the breaking and presumably has some control over it. The window pane undergoes a change as a result of the breaking activity and so the window pane matches with the "thing broken" participant, which has Change. But such a close correspondence is not a necessary condition for NP matching. Take, for instance,

16) a. The captain passed the straits.

b. The passengers passed the straits.

Presumably the subject participant in the lexical entry of pass has the feature Control:

pass: "passer" (Cause, Control), location passed ( $\varnothing)$

But although only the captain, and not the passengers, has control over the event, the mental representations of the passengers and the "passer" participant in the verb's lexical entry of pass are sufficiently similar to permit matching in 16b) despite the absence of Control.

In general, although inanimates lack control over an activity, NPs referring to them can match with a participant having the feature Control. Breaking, for instance, is normally predicated of persons, and the lexical entry of break has therefore a subject participant with the feature Control. Although it cannot be said to have any control, the falling branch can be the subject of break in 17), because of its similarity to the subject participant in its lexical entry.

17) The falling branch broke the window pane.

Similarly, the verb extinguish has a participant with Control, but can have not only an animate subject, as in 18a), but also an inanimate one, as in 18b).

18) a. The boy extinguished the camp fire.

b. The rain extinguished the camp fire.

Another feature that may be ignored in NP matching is Change. Consider

19) a. He broke his promise.

b. They dropped the plan.

In 19a), break is used in an extended sense to refer to the breaking of something immaterial: a promise is conceived of as something that is broken. Although the object participant of break, the "thing broken" has the feature Change, his promise can match with it, although no change occurs in the promise. Likewise, the object participant of drop has the feature Change (a dropped object changes its location), but although a plan cannot be said to change its location by being dropped, the plan in 19b) matches with the object participant of drop. In general, metaphorical extensions of verb meaning, as in 18)-19), are due to such "partial" matchings that ignore a specific feature. This is in line with the principle that features are not properties of NPs but of participants in the lexical entry of a verb.

\section{Similarity in Matching}

Not just any conceivable similarity suffices for NP matching (after all, practically everything is similar to everything else in some respect or other). Take for example the verbs stir and eat: stir: "stirrer" (Cause, Control), stirred material (Change) eat: "eater" (Cause, Control), eaten material (Change)

An instrument can be subject of stir, although only the person who wields it has control over the activity. Thus, in certain contexts, 20) may be acceptable. 
20) The spoon stirred the soup.

Because a spoon can be viewed as "doing" the stirring, the spoon in 20) matches with the "stirrer". But subjectivization of the instrument is not possible for some other verbs, like eat, because the similarity between the instrument and the subject participant is not large enough:

21) *The spoon ate the soup.

More is involved in eating than just bringing food to the mouth, which is all a spoon can do. The spoon therefore does not match the subject participant of eat. The same factor also accounts for the oddness of the asterisked sentences in

22) a. He walked into the hall with a crutch.

a'. *The crutch walked into the hall.

b. They listened to the music with earphones.

b'. *The earphones listened to the music.

c. She jumped over the fence with a pole.

c'. *The pole jumped over the fence.

Further, the similarity between a given NP and a participant must be not only large enough, but also greater than the similarity of any other NP in the sentence to that participant. This rules out

23) *The spoon stirred the soup by Fred.

The subject participant of stir has both Cause and Control. Fred is not only the cause of stirring, but is also in control, while the spoon can be viewed as causing the stirring but not as controlling it. Thus Fred fits the subject participant better than the spoon. Omitting by Fred results in the grammatical sentence 20).

As stated, Feature linking rules are defined in terms of features of participants in the lexical entry. However, such a rule does not operate directly on a participant with the required features, but on the NP that matches with this participant. For example, a Feature linking rule specifies that a NP that matches the participant with Cause is linked to sentence subject (i.e., is positioned before the verb, etc.). When Doris breaks the window pane, Doris matches the participant "breaker", and since the latter has the feature Cause, Doris has to be subject, as in 15).

The next section deals with linking in greater detail.

\section{Selection of Subject and Direct Object}

\section{Subject Selection}

In English and in many other languages, the lexical entries of almost all verbs include a participant that is linked to the sentence subject. We now take a closer look at the feature composition of the sentence subject and the direct object. Table 1 shows the combinations of subject and object features that we have encountered so far.

This table shows that a participant with the "default feature" $\varnothing$ never becomes subject. A necessary condition for a participant of a given verb to be linked to the sentence subject in an active sentence is that it has at least one of the features Cause, Control, Change or Attr-St. But is this also a sufficient condition? I now show that it is not.

\section{Feature Conflict?}

There are verbs with lexical entries having one of the above four features in both their participants, and there might appear to be a "conflict" between the features: Which participant is linked to the subject? There are four classes of such verbs:

a) Object participants with Change: The object participants of many verbs have Change, which is a feature that permits
Table 1.

Features of subjects and of direct objects.

\begin{tabular}{ccc}
\hline Subject participant & Object participant & Example \\
\hline Cause, Control, Change & (none) & run \\
Cause, Control, Attr-St & (none) & sit \\
Cause, Control & (none) & cry \\
Cause & (none) & snore \\
Cause, Control & Change & break \\
Cause & Change & frighten \\
Cause, Control & $\varnothing$ & accuse \\
Control, Attr-St & $\varnothing$ & pity \\
Control & $\varnothing$ & undergo \\
Change & $\varnothing$ & sustain \\
Attr-St & $\varnothing$ & contain \\
\hline
\end{tabular}

linking to the subject. The object participants of spill, pull, throw, and send involve changes of location; in those of break, mix, eat, and repair a change of state occurs; and the activity denoted by a verb like build, paint, sculpt, or write results in something coming into being, i.e., changing from non-existence to existence. These verbs might seem to involve a conflict between features that license linking to the subject: Change, on the one hand, and Cause and Control (the features characterizing the "spiller", "breaker", "builder", etc.), on the other.

b) Both subject and object participants with Cause: In the lexical entries of a few verbs, both the subject and the object participants have the feature Cause. For instance,

24) The guide is leading the tourists.

Leading implies that both the leader and his followers move, that their movements are (internally) caused by them and are under their control; that is, the followers, like the leader, have the features Cause, Control, and Change. This appears to constitute a feature conflict, since only one of the participants can be linked to the subject ${ }^{16}$. Another verb that has an object participant with Cause and Control is incite.

c) Intransitive verbs used causatively: For instance,

25) a. The lady is walking her dog.

b. The sergeant marched his men across the square.

When one walks a dog, the latter is walking, too. Likewise, not only the sergeant, but also the men march. The movements of the dog and of the men are internally caused, and in each 25a) and 25b) there are therefore two participants with Cause, only one of which can be realized as subject. Davis (2001) criticizes Dowty's (1991) theory for not accounting for sentence with such causative verbs.

d) Location subjects: Some verbs may have a location as subject, e.g.,

26) a. This room sleeps two students.

a'. Two students can sleep in this room.

b. This hall seats 150 listeners.

b'. 150 listeners can sit in this hall.

26a) and 26b) describe properties of the room and the hall,

\footnotetext{
${ }^{16}$ One might argue that the activity of the tourists is itself caused by the leader, and that such cases are best dealt with by introducing the construct "prior cause". A somewhat different solution will be proposed further on. The verb follow does not raise the same problem. The lexical entry of follow includes only one participant with Cause and Control: the follower (not the leader). A detective can follow a person without the latter leading him, and many of us occasionally follow instructions, rules, or examples.
} 
and so their subjects have the feature Attr-St. As a result of these properties, the students and the listeners, respectively, are able to sleep or sit, as stated in 26a) and 26b). Arguably, therefore, the object participants of the transitive sleep and seat (realized here by two students and 150 listeners) have the features Cause and Control $^{17}$. Here, again, there seems to be a conflict between features, and a Feature linking rule has to determine which NP becomes the sentence subject.

\section{Resulting Features}

Note that in the above four cases of apparent feature conflict, the features of the direct objects result from the event described by the verb. The object participants of spill, pull, break, mix, and so on, have the feature Change, because of the change that occurs as a result of the activity referred to by the verb. Similarly, in 24), the event referred to by lead results in the tourists' following the guide, and so the features Cause, Control, and Change of the object participant (matched with by the tourists) are resulting features. The features Cause, Control, and Change of the object participants of the causative walk and March in 25) are also resulting features. In 26), the students' potential sleeping in the room and the listeners' potential sitting in the hall result from the characteristics of the room and the hall. Participants with such Resulting features are not eligible for becoming the subject of an active sentence.

The term "resulting feature" can be defined as follows:

27) A resulting feature is a feature of a participant in the lexical entry of the predicate verb $V$, if and only if that feature is accorded to that participant as a result of the event referred to by $V$.

The occurrence of resulting and non-resulting features is summarized in Table 2. A feature can be a resulting feature in the lexical entry of one verb and a non-resulting one in that of another. Cause, Control, and Change can be either resulting features, as in some causative verbs (and then the participants to which they pertain become direct objects) or non-resulting ones (and then they become subjects). The features $\varnothing$ and Attr-St are always non-resulting; the former is linked to the direct object and the latter to the subject.

A linking rule for the subject can now be formulated in terms of four features and the distinction between resulting and nonresulting features:

28) A participant with at least one non-resulting feature
Cause, Control, Change or Attr-St is linked to the subject of an active sentence.

This rule applies to subjects of both transitive and intransitive verbs. It bars participants with the feature $\varnothing$ and those with resulting features from being linked to the subject. Passive sentences will be discussed below.

\section{"Symmetrical" Verbs}

Some verbs might seem to present difficulties for this formulation of the subject linking rule. Let us look at the verbs equal and resemble.

29) a. One yard equals .914 meters.

b. John resembles his father.

The subject participant of equal has the feature Attr-St; in the first sentence, something is attributed to one yard. One might want to argue that the object participant, .914 meters, also has Attr-St, and that there is thus a feature conflict. But note how awkward .914 meters equals one yard sounds. To provide information about meters it would be more natural to say One meter equals... The sentence does not say anything about .914 meters, although one can of course infer from it something about this measure of length. The object participant of equal has therefore the "default feature" $\varnothing$ and not Attr-St. The same reasoning applies to resemble. 29b) attributes a state to John, not to his father (John's father resembles John would sound strange). On the psychological asymmetry of similarity statements see Tversky (1977: p. 38).

The moral is that one must distinguish between what is said in a sentence and what is implied by it. Feature assignment is independent of whatever can be inferred from the event or situation described by the sentence.

There are also quasi-symmetrical activity verbs, as in

30) a. Erwin married my sister.

b. My sister married Erwin.

Both these sentences have the same truth value, but in many situations they are not interchangeable. When Erwin's parents are furious that he married my sister, one does not say that they are furious that my sister married him. The two sentences $30 \mathrm{~b}$ ) and 30a) do not say the same; one can at most infer one from the other. Only the subject participant of marry, and not its object participant, has the feature Cause ${ }^{18}$.

The same holds true of the lexical entries of meet (in one of

Table 2.

Examples of resulting and non-resulting Cause, Control, Change, and Attr-State*

\begin{tabular}{|c|c|c|c|}
\hline \multirow[t]{2}{*}{ Feature } & \multirow{2}{*}{$\begin{array}{c}\text { Subject participant } \\
\text { Non-resulting feature }\end{array}$} & \multicolumn{2}{|c|}{ Object participant } \\
\hline & & Non-resulting feature & Resulting feature \\
\hline Cause and/or Control & $\begin{array}{c}\text { cry } \\
\text { undergo }\end{array}$ & - & lead, seat, walk causative \\
\hline Change & melt & - & break, lead, walk $k_{\text {causative }}$ \\
\hline Attr-St & contain & - & - \\
\hline$\varnothing$ & - & accuse & - \\
\hline
\end{tabular}

\footnotetext{
${ }^{17}$ The causative form illustrated in 26) is found in only a handful of verbs. Neither the elevator stands four adults nor the tent lies six boy scouts is grammatical. Children learning English as their native language sometimes over-generalize the causative construction to such verbs (Bowerman \& Croft, 2008).

${ }^{18}$ In a psycholinguistic experiment, Kasof and Lee (1993) found that when presented with a sentence like Car A collides with car B, people judged Car A to have been moving faster than Car B. A series of experimental studies of symmetrical and apparently symmetrical verbs has been conducted by Gleitman et al. (1996).
} 
its uses) and fight. The subjects and objects in sentences with these verbs cannot always be interchanged with impunity: If a young boy met a pop star, it would be odd to say that the pop star met him, and if the government fights poverty, it is not the case that poverty fights the government.

\section{Direct Object Selection}

\section{Semantics of the Object Category}

We saw in Table 2 that a participant with the "default feature" $\varnothing$ is always linked to the direct object. It would be desirable to find a way to define this feature positively in terms of a property or properties common to all object participants having $\varnothing$; but such a characterization in semantic terms seems to be unattainable. Already Jespersen (1933, Section 11.3) observed how difficult it is to define the relation of the object to the verb. That an entity is referred to by a direct object does not imply that it is in motion or undergoes a change of state. In measure the width of the table, the width is neither effected nor affected, nor is it the Goal of the action in any sense. The object participant of measure shares the "default" feature $\varnothing$ with the object participants of many other verbs, for instance, with those underlying lack money, answer the door, relate the incident, avoid the rush, imitate a novelist, and with the direct object participants of deny, describe, forgive, revenge, regret, study, admit, prove, see, like, and many more. There seems to be no common semantic denominator of all these object participants (see Levin 1993; Levin \& Rappaport Hovav, 2005: pp. 27-28; Schlesinger, 1995: pp. 164-166). Hence the "default feature" can be defined only negatively, as the feature that is neither Cause, Control, Attr-St, nor Change.

How, then, is the direct object selected? I propose that features of participants determine selection of the subject according to rule 28), and the remaining participant, if there is one, is linked to the direct object ${ }^{19}$. In other words, the direct object is a default category (cf. Levin \& Rappaport Hovav, 1995: p. 154). This view of object selection is based on the already mentioned assumption that a lexical entry of a verb has at most two participants (but see note 26 for possible exceptions). This assumption is motivated also by other, independent, considerations, as will be shown in the section on Roles of NPs, below. But first let us clarify some questions concerning object selection.

\section{Converse Verbs}

Above I discussed Grimshaw's (1990) analysis of the pair of verbs frighten and fear. Let us see now how these verbs are analyzed in the present framework. Grimshaw's example 14) is repeated here:

14) a. The storm frightened us.

b. We feared the storm.

The relevant lexical entries are:

\footnotetext{
${ }^{19}$ Oblique objects will be discussed in the section on Roles of NPs, below. Cognate objects are not realizations of any participant in the lexical entry. The verbs laugh, live, and die do not have an object participant (they are normally used intransitively), but each of them may have a direct object that repeats the information in the verb: laugh an anguished laugh, live a good life, die a violent death; consider also sculpt an impressive sculpture. It appears that such cognate objects result from a realization rule that introduces a modifier of the verb, and they occur mainly when no adverb can do the job: Living a good life is not the same as living well, sculpt an impressive sculpture is not the same as sculpting impressively, and an anguished laugh cannot be replaced by ${ }^{*}$ laugh anguishedly.
}

frighten: the entity that frightens (Cause), the one who is frightened (Change)

fear: the one who fears (Attr-St), the feared entity (ø)

In 14a), "the entity that frightens" has the feature Cause, and so is selected as subject, and the remaining participant, "the one who is frightened", is linked to the direct object. In 14b), "the one who fears" is said to be in a state and so has Attr-St, which qualifies we for subject position, and so "the feared entity", the storm, becomes direct object.

Two kinds of objections to this analysis might be made:

a) A state is attributed to "the one who is frightened" (in the lexical entry of frighten). Hence this participant should have the feature Attr-St, just like the participant "the one who fears" in the lexical entry of fear. Accordingly, Attr-St would here be a resulting feature of "the one who is frightened".

However, an activity or event cannot result in a state, but only in a change of state. "The one who is frightened", is said to have changed from not fearing (i.e., may have evinced no fear before the frightening event) to fearing, and so has the resulting feature Change. Attr-St is never a resulting feature (see Table 2).

b) "The feared entity" in the lexical entry of fear, the storm in $14 \mathrm{~b}$ ), is what causes the fear and so should be assigned the feature Cause, rather than ø (just like "the entity that frightens" in the lexical entry for frighten). "The feared entity" would thus compete with "the one who fears" for subject position.

But the storm referred to in We feared the storm is not the cause of the fear; rather, it is its content, just as it can be the content of mental states like expecting, imagining, enjoying, and hating, and not their cause:

31) a. We expected the storm.

b. We imagined the storm.

c. We enjoyed the storm.

d. We hated the storm.

The storm cannot be the cause of expecting, since causes do not operate backward in time, and a storm does not cause anyone to imagine it. Verbs describing cognitive states other than ones referring to emotions also have object participants pertaining to content rather than to causes:

32) a. He remembers his uncle.

b. He forgot his wallet.

The uncle may have long since died, and the wallet can hardly be held responsible for being forgotten.

The pair of verbs please and like will be analyzed like frighten and fear, and so will persuade and believe (Peter persuaded Bill and Bill believed Peter ${ }^{20}$. Some other converse verbs are dealt with in the section on Roles of NPs, below.

\section{Object Elision}

There are sentences in which the object participant of the lexical entry of a verb is not realized. Some transitive verbs, among them eat, drink, help, leave, permit elision of the direct object. Both Percy is eating an apple and Percy is eating are grammatical.

"Symmetrical" verbs, like marry, fight, etc., also permit elision of the direct object. If their subject is a conjoint, the verb may be understood in one of two ways: either as reciprocal, as in 33a), where each other is elided, or not, as in 33b), where

\footnotetext{
${ }^{20} \mathrm{Cf}$. Fillmore (1968). The fact that there is no Actor in either please or like, led Jackendoff (1987: p. 397) to conclude that the difference between them is "lexically determined".
} 
direct object NPs are elided.

33) a. John and Jill married.

b. John and his sister married.

In such "symmetrical" verbs, each NP in a conjoint must match in the same way with the subject participant of its predicate verb. The reason why The drunk and the lamppost embraced, is ungrammatical, is that the subject participant of embrace has the features Cause and Control, the drunk matches with this participant in respect to both these features, whereas the lamppost would match it merely "partially".

Object elision in several other verbs, e.g., dress, shave, bathe, wash, hide, and feed, leads to the verb's being construed as reflexive, as in 34b):

34) a. Paula dresses her doll.

$$
\text { b. Paula dresses. }
$$

\section{A Note on Dowty's Theory}

On the present theory, four features and the distinction between resulting and non-resulting features are sufficient for subject and direct object selection. The definitions of the four features differ in some respects from those of Dowty's (1991) features of the Proto-Agent, and some of Dowty's features (e.g., "sentience") are not among the features included here.

Kako (2006) has found that the grammatical function of a NP in a sentence could serve as a clue as to Dowty's features, thus providing evidence for the psychological validity of the latter. However, that speakers are aware of these syntactic-semantic correspondences does not mean that subject selection is based on them. The rule in 28) is simpler than Dowty's rules, since it states that any one of the specified features is a sufficient condition for linking to the subject, whereas in Dowty's system the number of features characterizing his Proto-Agent and ProtoPatient has to be taken into account (and this has also implications for first-language acquisition; see the last section).

\section{Roles of NPs}

As stated, a lexical entry has either one or two participants, and these are realized as subject and (in entries with two participants) direct object. Other NPs in a sentence, notably oblique objects, do not match participants. In the following we will see what motivates this claim.

\section{The Insufficiency of Features}

Suppose for a moment that not only two, but all arguments of a verb are realizations of participants. Then there would be several serious difficulties for subject and object selection, as will be shown now.

\section{Causal Phrases}

A prepositional object may refer to the cause of the event or situation described by the verb. Here are some examples:

35) a. The king died by the sword.

b. The old man died through neglect.

c. The explorer died from exhaustion.

d. The child thrives with love.

Suppose that the sword in 35a) were to be matched with a participant of die; then it would have a non-resulting feature Cause (the sentence mentions no other entity that causes the sword's activity). Accordingly, the sword would have to be the subject, because the king matches with a participant with a resulting feature (Change). The same goes, mutatis mutandis, for 35b), 35c), and 35d).

Sentences like these are also an obvious embarrassment for a thematic-roles theory. The NPs in the prepositional objects of 35) refer to causes, and these should be higher in the hierarchy than the thematic roles of what are here realized as subjects. Compare 35a), 35b), and 35c) to their near-paraphrases, The sword killed the king, Neglect killed the old man, and Exhaustion killed the explorer. Why, then, should the sword, neglect, exhaustion, and love in 35) not be subjects?

Dowty's (1991) theory apparently cannot provide an explanation either. True, the subjects of 35) are all animate and sentient, and might be good candidates for proto-agency. But the subjects in 36) are inanimate, hence not sentient; they do not cause a change, nor do they necessarily move, and so don't even come near to being proto-agents. In fact, the oblique objects in 36a)-36d) do have some of these entailments and thus should be proto-agents:

36) a. The plants withered for lack of water.

b. The law passed thanks to the prime minister.

c. Prices rose due to foreign investors.

$d$. The alarm went off because of our cat.

e. The shack collapsed of old age.

\section{Converse Verbs, Again}

Converse verbs present what Dowty (1991: p. 379) calls a "puzzle" for a thematic role approach. The two sentences in 37) are near-paraphrases; Ben seems to have the same thematic role in both, and so has Amy. What accounts for the fact that the two sentences have different subjects? The same question arises in the framework of feature theory. When Amy sells a car, she causes the selling and has control over it, regardless of whether the transaction is described as in $37 \mathrm{a}$ ) or as in $37 \mathrm{~b}$ ), and so Amy should be subject in both. A similar argument can be made concerning the buyer, Ben.

37) a. Amy sold a car to Ben.

b. Ben bought a car from Amy.

\section{Alternating Verbs}

Alternations present difficulties for thematic hierarchies. Some kinds of alternations appear to pose problems also for our feature-based approach, for instance,

38) a. The fountain spouts water.

b. Water spouts from the fountain.

39) a. He hit the wall with a hammer.

b. He hit the hammer against the wall.

If spout in $38 \mathrm{~b}$ ) had two featured participants, the fountain would match with the subject participant just as it does in 38a). So why is the fountain in subject position in 38a) and not in 38b)? Similarly, in 39), a hammer may be thought to have the same features in both sentences, and so should have the same syntactic function in both.

\section{Instruments}

40) a. This key will open the door.

b. The door will open with this key.

If the key in 40b) were a realization of a participant in the lexical entry of open, it might be expected to have the same features in both a. and b. Why, then, is the key subject in a. but prepositional object in b.? A theory based on thematic hierarchies encounters the same problem, because in both sentences, 
the key has the Instrument role, and in both the door has the same role (Theme?).

Any theory based on a thematic hierarchy will presumably provide a separate solution for each of the difficulties posed by 35)-40). Grimshaw's (1990) treatment of converse verbs like fear and frighten can perhaps be adapted to cover cases like sell and buy in 37), but will not be applicable to causal prepositional phrases like 35)-36). Likewise, treatments of the locative alternation (e.g., Beavers, 2006; Dowty, 1991: pp. 587-592; Hopper and Thompson 1980: 262) and Fillmore's (2003: pp. 222-224) account of verbs like hit and break are not applicable to other cases discussed in the foregoing. In the next sub-section, I propose a single solution to all the difficulties described here. The linking system, it will be argued, relies neither on features alone nor on thematic roles alone; both features and thematic roles are needed.

\section{Roles without Hierarchies}

The lexical entry of a verb, I have argued, contains at most two participants with features, and these are linked to the subject and (when there are two) the direct object. A sentence may of course include NPs besides subject and object, notably oblique objects, but these do not match any one of the participants in the verb's lexical entry (even in those verbs that have an obligatory oblique object). Instead, they express thematic roles, or roles, as they will be called here for short. In other words, only arguments that are realized as subjects and direct objects (and not adjuncts) appear in the lexical entry as participants with features. Thus, give has three arguments, but only two featured participants (the "giver" and the thing given); the Recipient is a role that is not based on a participant.

Subjects and direct objects are selected on the basis of Feature linking rules and thus do not depend on precedence relations between thematic roles. All other arguments have roles and are realized in accordance with Role Linking Rules, to be discussed further on. To illustrate:

41) a. After lunch, Anne threw the ball over the fence.

b. After lunch, Anne threw the ball to Clara.

The lexical entry of throw is

throw: "thrower" (Cause, Control), object thrown (Change)

Feature linking rules assign the NP Anne, which matches the participant with Cause and Control, to subject position, and the ball, to direct object position. Of the remaining NPs, lunch has a temporal role, the fence in 4la) has a locative role, and Clara in 41b), a Recipient role. Role linking rules determine that after precedes lunch, over precedes the fence in 41a), and in 41b) to precedes Clara.

\section{Problems Solved}

Positing roles alongside features provides a straightforward solution for the difficulties discussed in the foregoing:

a) Causal phrases: In 35)-36), the lexical entries of die, thrive, wither, pass, rise, go off, and collapse have each a single participant, which is linked to the subject. The NPs realized as prepositional objects are adjuncts; they have causal roles and do not match with any featured participants. Hence they are not candidates for subject-hood.

b) Converse verbs: The lexical entries of sell and buy are:

sell: seller (Cause, Control), thing sold (Change)

buy: buyer (Cause, Control), thing bought (Change)
In addition to subject and direct object, the sentences in 37) contain NPs with roles: the Recipient or Goal (the buyer, Ben), and the Source (the seller, Amy). These are adjuncts realized as prepositional phrases. Similar analyses can be made of the uses of other pairs of converse verbs: teach and learn, lend and borrow, and give and receive.

Gropen et al. (1991a) present an analysis of fill and pour in terms of event structures. On the present approach, these do not have to be resorted to. Consider:

42) a. John fills the glass with water.

b. John pours water into the glass.

The lexical entries of these verbs are:

fill: the one who fills (Cause, Control), the receptacle filled (Change)

pour: the one who pours (Cause, Control), the material poured (Change)

The "receptacle" in fill undergoes a change of state (from empty to full), and the "material" in pour, a change of location. 42a) shows that a sentence with fill may have, in addition to the subject and direct object, a NP with a role (Theme? Material?), and $42 \mathrm{~b}$ ) shows that a sentence with pour may include a NP with the role Goal.

c) Alternating verbs: Most alternations apply to only a small class of verbs and are based on different sub-entries in the lexical entry of the verb. Spout, for instance, has a sub-entry containing two participants: "source of spouting' (the internal Cause) and "the material spouted" (with Change). This sub-entry underlies The fountain spouts water 38a). Another sub-entry of spout underlies Water spouts from the fountain 38b) and has only one participant with the feature Change. The prepositional object from the fountain is not based on a participant of spout, but has a role, and is realized as an oblique object. The verb hit also has two sub-entries. In the sub-entry underlying 39a), the object participant is "the location hit" and in the one underlying 39b), "the instrument of hitting". Both sentences have NPs with roles (a hammer and the wall, respectively), and roles do not compete for subject and direct object positions ${ }^{21}$.

d) Instruments: The verb open has two lexical sub-entries, a transitive one, as in 40a), and an intransitive one, as in 40b):

open $_{1}$ : the opener (Cause, Control), the thing opened (Change) open $_{2}$ : the thing that becomes open (Change).

In 40a), this key matches "the opener" of open $_{1}$ (by partial matching, because the key has no control). $40 \mathrm{~b}$ ), however, is based on open 2 , and only the door realizes a participant; this key has a role (Instrument), and so its syntactic function is not determined by the linking rules for subject and direct object.

\section{Passives with by-Phrases}

$B y$-phrases are prepositional objects. They can be assigned various roles, as shown in Table 3.

By contrast, the subjects of the corresponding active sentences do not have roles, but features. Table 3 shows that when the direct object of an active sentence has the feature Change, the subject of the corresponding passive sentence also has

\footnotetext{
${ }^{21}$ As pointed out by Fillmore (1970), there is no similar alternation for the verb break (*He broke the hammer against the fence). The reason seems to be that broke the hammer can be construed as something done to the hammer, and speakers avoid such a construal. For hit the hammer this is not a likely construal, since people rarely hit hammers (they are more likely to break them). There is some psycholinguistic evidence showing that the plausibility of an erroneous construal in the course of processing does affect the judged acceptability of a sentence (Schlesinger, 1977: pp. 211-215).
} 


\section{M. SCHLESINGER}

Table 3.

Passive sentences with by-phrases.

\begin{tabular}{|c|c|c|c|c|c|c|}
\hline & \multicolumn{3}{|c|}{ Active } & \multicolumn{3}{|c|}{ Passive } \\
\hline & Subject particip. & Object particip. & Example & Subject particip. & Role of $b y$-phrase & Example \\
\hline 1 & CA CO & $\mathrm{CH}$ & Doris broke the window. & $\mathrm{CH}$ & Agent & The window was broken by Doris. \\
\hline 2 & $C A(C O)$ & $\mathrm{CH}$ & The tsunami broke the window. & $\mathrm{CH}$ & Natural Force & The window was broken by the Tsunami. \\
\hline 3 & $C A(C O)$ & $\mathrm{CH}$ & A stone broke the window. & $\mathrm{CH}$ & Instrument & The window was broken by a stone. \\
\hline 4 & $C A(C O)$ & $\mathrm{CH}$ & The storm frightened us. & $\mathrm{CH}$ & Stimulus & We were frightened by the storm. \\
\hline 5 & $A T T$ & $\varnothing$ & His friends admire him. & $A T T$ & Experiencer & He is admired by his friends. \\
\hline 6 & $A T T$ & $\varnothing$ & This room sleeps two students. & - & - & - \\
\hline 7 & $A T T$ & $\varnothing$ & One yard equals .914 meters. & - & - & - \\
\hline 8 & $\mathrm{CACOCH}$ & $\varnothing$ & They arrived at the airport. & - & - & - \\
\hline 9 & - & - & - & ATT & Manner & The solution was found by chance. \\
\hline
\end{tabular}

Abbreviations: $\mathrm{CA}=$ Cause $\mathrm{CO}=$ Control $\mathrm{CH}=$ Change; $\mathrm{ATT}=$ Attr-St. $(\mathrm{CO})$, in parenthesis, indicates that the subject participant has Control which is lacking in the specific NP (and supplied by NP matching).

Change $e^{22}$. When the direct object of an active sentence has the feature $\varnothing$, the subject participant of the corresponding passive sentence has the feature Attr-St. When a by-phrase has the Manner role, as in line 9 of the table, there is no corresponding active sentence.

As shown in lines $6-8$, there are also active sentences without corresponding passives (either with or without by-phrases). The reason is that unlike all subjects of passive sentences, which have either Change or Attr-St, the suppositional subjects of such passive sentences would not match with any one of these features: Nothing of interest would be asserted of .914 meters by .914 meters are equaled by one yard, or of the airport by the airport was arrived at by them, and so it would be infelicitous to ascribe to these NPs the feature Attr-St. This is also the reason why the verbs possess, have, lack, suit, become, and fit normally do not passivize. See Schlesinger (1995: pp. 131138 ) on this and similar constraints on passivization.

\section{Distinguishing Direct from Oblique Objects}

The theory proposed here is more parsimonious than one based on thematic hierarchies. This simplification comes at the price of a distinction between two sets of semantic notions, features and roles, and two corresponding classes of rules: Feature linking rules and Role linking rules (to be dealt with further on. Let us see now whether there is any semantic criterion determining which arguments are represented by features in a lexical entry and which are not.

In many sentences, direct objects seem to be, as it were, more intimately related to the verb than oblique objects. One can throw a ball without throwing it to any specific place or person, and so the ball in 41) is direct object, whereas over the fence and to Clara are not. That direct objects are more central to the verb's meaning is the view of, inter alia, Jackendoff (1990a: 449), who states that the first object of a ditransitive verb (e.g., John in give John a book) is not a direct object, since it "expresses a semantic role that is not an essential part of the verb's meaning" in the way direct objects are.

\footnotetext{
${ }^{22} \mathrm{Or}$, in the case of an adjectival passive, Attr-St (e.g., The vase is broken, in the sense of "broken vase"). One might conceive of active and the corresponding passive sentences as stemming from two sub-entries in the lexical entries of the verb $\mathrm{V}, \mathrm{V}$ and $b e \mathrm{~V}$ en, and the adjectival passive as based on yet another sub-entry. Alternatively, the passive may be viewed as a result of a generalized lexical rule. This question will be left open here.
}

But essentiality is anything but a reliable criterion. Thus, for filling to take place, there has to be, in addition to the agent, a specific vessel that is filled and a material it is filled with. All three are essential for filling to occur, but only the vessel appears as direct object; cf. 42). Buying requires, besides the buyer and an item bought, a seller and money or a commodity given in exchange. In the absence of any one of these, buying cannot be said to have taken place, but the seller and the money given in exchange are expressed as oblique objects ${ }^{23}$.

Another distinguishing property that has been proposed is affectedness. A case in point is the locative alternation:

43) a. She sprayed the wall with paint.

b. She sprayed paint onto the wall.

The first sentence, but not the second, suggests that the wall is wholly covered with paint. It has been argued that the direct object carries with it a sense of completeness (Anderson 1971; Fillmore 2003: 226), as evidenced also by the pair search in the room, search the room, and denotes the "completely affected" (Hopper \& Thompson, 1980: p. 262; see also Beavers, 2006), "wholly involved" (Levin \& Rappaport Hovav, 2005: p. 209) entity. As Gropen et al. (1991a: p. 162) remark: “... the most natural interpretation of a state change is that it is the entire object that undergoes the change, rather than one part...". Accordingly, when the wall is completely painted, 43a) is more appropriate than 43b). This does not take us very far, however. It does not explain other alternations. For instance, why can the hammer and the wall each be either a direct or an oblique object in 39)?

A factor related to affectedness is success of the activity. Examples of the conative alternation, like push the table, push at the table and shoot the bird, shoot at the bird, indicate that often the direct object, but not the oblique one, signals success of the activity. This factor can account only for alternations where one sentence has "verb $+a t$ " (like, e.g., push at) and the other only "verb" (push).

A semantic distinction between direct and oblique objects

\footnotetext{
${ }^{23}$ True, in these particular instances the oblique objects can be elided when their identity is known or is not of sufficient interest to be reported. But this does not indicate that they are less essential than direct objects; in fact, direct objects are also often elided (as in He is eating), whereas the oblique objects of many verbs cannot be (cf. put the book on the shelf). Consider also that some verbs, for instance, rely and belong, require a prepositional object, but do not have a direct one.
} 
has been proposed by Dowty (1991: p. 576) in his Corollary 2: The non-subject argument with the greater number of ProtoPatient properties becomes direct object and the one with a smaller number becomes oblique or prepositional object. This proposal, again, does not account for alternations where the direct and prepositional objects can be interchanged. For instance, in both 39a) and 39b), the hammer has the Proto-Patient properties "undergoes change of state" (it is in motion) and "causatively affected", whereas the wall has only one: "stationary". On Dowty's proposal, this would rule out 39a), where the hammer is not the direct object but a prepositional object. Neither can Dowty's hypothesis account for crosslinguistic differences: There are English verbs taking a direct object and their French translation equivalents, an oblique one (discuss, direct object, discuter, oblique, or enter vs. entrer), or vice versa (long, oblique, vs. desirer, direct object) ${ }^{24}$. Further, the alternates of the following pairs do not differ in respect to ProtoPatient entailments: blame $X$ for $Y$, blame $Y$ on $X$, present $X$ with $Y$, present $Y$ to $X$, and strip $X$ of $Y$, strip $Y$ from $X$. Finally, some verbs can have either a direct or a prepositional object: John meets X, John meets with X, Jack consults X, Jack consults with $X$, Jerry confesses his theft, Jerry confesses to his theft, Julie ponders the alternatives, Julie ponders over (or on) the alternatives (Schlesinger, 1995: pp. 175-179). Apparently, the direct and prepositional objects in each of these pairs do not differ in respect to their "entailments".

It appears therefore that the lexical entries of many verbs stipulate what becomes a direct rather than an oblique object $\mathrm{t}^{25}$. In the final section, we will see how the language learner masters the distinction between direct and prepositional objects.

\section{Role Linking Rules}

\section{Feature Linking Rules and Role Linking Rules}

A Feature linking rule is defined in terms of features. It states that a participant with the non-resulting feature $F$ will be realized as the sentence subject. Each Feature linking rule operates on the NP that matches with a participant with the feature $F$. Role linking rules, by contrast, do not take such an indirect route and do not require NP matching. A Role linking rule may state, for instance, that a NP having role $R$ is preceded by the preposition $P$ and can appear in such and such a syntactic combination. While features pertain to participants and do not take into account the sentential content, roles are independent of the lexical entry of the verb and its participants, and Role linking rules depend entirely on the role expressed by the prepositional phrase: a location (in the garden) a purpose (for the garden), a cause (because of the garden), etc.

\section{Alternative Role Linking Rules}

Sentences with ditransitive verbs, like 44), are apparent counter-examples to the claim that lexical entries have one or,

\footnotetext{
${ }^{24}$ Witman (2000) found such discrepancies in close to 10 percent of a sample of pairs of English and French verbs that were translation equivalents. In Hebrew, the tendency of verbs to take an oblique object is stronger than in either one of these languages, and the discrepancies were larger: 11.5 percent for Hebrew and English and 14.6 percent for Hebrew and French.

${ }^{25}$ Many of the facts discussed in this sub-section are also difficult to explain in a non-ad hoc manner by any theory based on a thematic hierarchy, and presumably such a theory will also have to resort to the assumption that they are stipulated by the lexical entry. In recent years, several writers have shifted the burden of accounting for linguistic regularities from general rules to lexically specific ones (see, e.g., Chomsky, 1995; Ninio, 2006).
}

at most, two participants:

44) Anne threw Clara the ball.

In this sentence there are three arguments: besides the "thrower" and the "object thrown" there is the recipient, Clara. Both Clara and the ball, are often regarded as direct objects, but Jackendoff (1990a: p. 449) argues against this. Hudson (1992) presents further evidence against regarding the indirect object as a sort of direct object, and also argues against regarding it as allied to oblique objects. Instead, he conceives of the indirect object as a separate kind of object.

It is proposed that 44), like any other sentence with a transitive verb, has only two participants, a subject participant (here Anne), and an object participant (here the ball), and Clara has a role, the Recipient, just like Clara in

45) Anne threw the ball to Clara.

The Recipient role, then, has two alternative realizations: one with a preposition and positioned after the direct object, as in 45 ), and one without preposition and positioned before the direct object, as in 44$)^{26}$.

\section{Some Constraints on Role Linking Rules}

Only some verbs permit a choice between the double object construction, as in 44), and these belong to certain semantically defined classes, such as change of possession verbs (like give send, buy, sell) and verbs of communication, like tell, show, ask, teach, write, read, e-mail. Within the latter class there are semantically homogeneous sub-classes, for instance, "manner of speaking" verbs (e.g., shout, murmur, scream), which rule out the double object construction (Gropen et al., 1989; see also Jackendoff, 1990b: pp. 194-200; Pinker, 1989; and Shibatani, 1996. Evidence for a processing factor has been found by Schlesinger, 1977: pp. 204-215). The Recipients of some other verbs, like ask, call, and elect, require the double object construction and are usually not expressed as prepositional objects ${ }^{27}$.

A Role linking rule, or one of two alternative Role linking rules, then, may be blocked for certain semantically defined classes of verbs (and in some cases, for certain individual verbs). This shows that Role linking rules may be sensitive to the meaning of the main verb, where "meaning" refers not just to the participants, note that tell and shout have similar participants with the same features, but to the entire mental representation of the verb's meaning in the lexical entry.

\footnotetext{
${ }^{26}$ See the extended discussion by Rappaport Hovav and Levin (2008), and Beavers (2006) for a different treatment of indirect and oblique objects. In German, indirect objects, like most oblique objects, are in the Dative case, unlike direct objects, which are in the accusative. However, some verbs, like lehren (teach) fragen (ask), and kosten (cost) are exceptions: In the German translation equivalents of Jessica taught my son math, she asked my son a silly question, The yacht cost my son a fortune, the NP my son is in the accusative case. Similarly, the verbs teach and ask in the Hebrew translation equivalents of these sentences require $m y$ son to be preceded by et, which introduces the direct object, rather than by the preposition $l$-, which introduces an oblique object. Further, English indirect objects can be paraphrased by prepositional objects with to and for (give this to..., cook this for...), whereas asked my son is paraphrased by of (ask... of my son), and cost my son cannot be paraphrased with a prepositional object. In fact, unlike verbs having indirect objects, ask and cost do not involve any Recipient or Beneficiary. Perhaps, therefore, the lexical entries of ask, cost, and teach should be regarded as exceptions in that they have two object participants.

${ }^{27}$ But see Rappaport Hovav and Levin (2008). A further complication: For certain kinds of direct objects (mainly those denoting immaterial entities), the double object construction will be unacceptable with some ditransitive verbs. For instance, one cannot say *Jenny gave a headache/ trouble/ good advice to Richard. This may be due to the fact that the verb is used here in a special sense.
} 


\section{What Roles Are There?}

Thematic roles are usually conceived of as determining argument selection. On the present theory, selection of subject and direct object is taken care of by features and Feature linking rules, whereas roles are required to account for other linguistic regularities, among them assignment of prepositions. To ask for a list of roles is therefore tantamount to asking for a list of semantic distinctions that make some linguistic difference in the realization of roles (cf. Dowty, 1991: p. 562).

Once the question is formulated in this way, it becomes clear that there must be a far larger number of roles than those included in any thematic hierarchy. A NP describing the purpose of an activity, for instance, appears with certain prepositions (for, in order to, etc.), and so Purpose has to be a role by itself, and so has Manner, (as in with care). These roles are not included in any current proposal for thematic hierarchies, to my knowledge.

Some established thematic roles must be split into several roles or several sub-roles. This becomes evident on considering the prepositions that are appropriate in each instance. For instance, the role that goes under the name "Location" is in fact a set of roles or sub-roles, each requiring a different preposition (and not only those for the Source and Goal roles, i.e., "Location to" and "Location from"). In 46a) and 46b), for instance, three prepositions appear, and these cannot be interchanged:

46) a. They met in Melbourne on Main Street at the corner.

b. The fire started in Australia on a farm at (or near) the barn.

c. *They met at Melbourne in Main Street on the corner.

d. *The fire started at Australia at a farm on the barn.

The triplet of prepositional phrases with in, on, at is ordered according to the size of the specified location. This is also the case when only a single location is mentioned: One does not say *at Melbourne or *in Main street. There are thus three different Location roles, corresponding to the size of the specified location.

The same holds true for temporal roles:

47) a. In February on a Monday at eight in the evening.

b. In 1976 on May 16 at noon.

Again, the prepositions in, on, and at have to be applied according to (among others) the extent of time referred to; in 47) no other permutation of prepositions is permitted. We thus have to distinguish between three temporal roles (in addition to the temporal roles expressed by oblique objects with prepositions like during, since, until, after etc.).

As another example, take the closely related roles, Instrument and Natural Force. In the absence of an animate agent, NPs denoting the instrument and a natural force can be realized either as prepositional phrases, as in $48 \mathrm{a}$ ) and $48 \mathrm{~b}$ ), or (because they are causes) as sentence subjects, as in 48c) and 48d):

48) a. He scratched the stone with a hammer.

b. The window was shattered by the storm.

c. The hammer scratched the stone.

d. The storm shattered the window.

However, when they function as subjects, the instrument or the natural force cannot deploy another instrument:

49) a. *The hammer scratched the stone with a chisel.

b. *The storm shattered the window with a tree branch.

Exceptions are instruments and natural forces that effect a change by dint of a proper part of themselves, as in

50) a. The car scraped the tree with its fender. b. The Tsunami destroyed the area with its high waves.

"Proper part of Instrument" and "Proper part of Natural Force" thus function as sub-roles of Instrument and Natural Force.

These examples suggest that the number of thematic roles in the present system greatly exceeds that of the roles commonly envisaged by theories involving thematic hierarchies.

To summarize, our system differs from many current ones in that it does not resort to any thematic hierarchy to account for the realization of arguments. There are two types of semantic notions, featured participants in the lexical entry of a verb, and roles, and correspondingly, two types of linking rules: Feature linking rules, which select subjects and direct objects, and Role linking rules, which determine the expression of other syntactic functions, notably oblique objects. We have seen that some support for this view comes from the fact that it affords simple explanations for some linguistic phenomena which pose difficulties for current theories. In the next section I show that it also affords a simpler theory of first language acquisition.

\section{Implications for Language Acquisition}

Grammar and language acquisition theory are interdependent: A grammar must be learnable, and an acquisition theory must show how the native language learner attains the adult linguistic system. In the following, I outline the way children might learn the semantic-syntactic mapping of the English language. Then the semantic feature theory and a linguistic theory based on thematic roles will be compared in respect to ease of acquisition.

\section{Acquiring Features and Feature Linking Rules}

The semantic features proposed in this paper are rooted in the child's cognitive equipment. Notions like change, cause, and control are deployed by the young child in making sense of events in her environment (see Leslie \& Keeble, 1987 on causation; Premack, 1990 on animacy and causality; Gelman \& Opfer, 2002 on cause and motion). But that a feature is within the cognitive compass of the small child does not suffice. The question that remains for an acquisition theory to deal with is how the child finds out just which notions out of several possible ones (like, e.g., "big" and "red") play a part in the formulation of syntactic regularities. Further, that a child has the notion of, say, causation and understands that a given event causes another does not mean that she has a semantic feature Cause (see Schlesinger, 1995: pp. 4-27 for a discussion of the distinction between cognitive notions and semantic categories). Lastly, notions pertain to the events or situations referred to, whereas features inhere in lexical entries; a participant in a verb's lexical entry may have a feature $F$, regardless of the situation referred to by the verb. The problem for an acquisition theory, then, is: How do notions like "cause" and "control" develop into semantic concepts, namely, features?

I propose that the development of a feature concept goes hand in hand with the formation of Feature linking rules that apply to it. Observing how a participant is expressed in the sentence leads to the formation of a linking rule and at the same time draws attention to the feature of this participant. The following sketchy remarks describe, without hypothesizing any innate semantic concepts, the steps by which this might come about. 


\section{Mini-Rules}

The child who comprehends an utterance like Jane pushes the baby carriage perceives a scene in which there are a pusher and a "pushee" between which an activity (pushing) takes place. The child's encounter with additional push-sentences gradually leads to two results: a) the meaning of push, i.e., the "scene" of this activity and of the participants involved, is stored in her lexical entry for push, and b) she records a lexically specific rule, to be called here a mini-rule, to the effect that the word referring to the pusher appears before the word $p u s h^{28}$. When the child then intends to comment on another incident of pushing, she will access the lexical entry of push and apply this mini-rule (the issue of direct-object realization will be discussed further on. Observe that at this stage no general notions like causation or control need be involved but merely the mental presentations of a pusher and a "pushee", and these are integral parts of the verb's meaning.

Some evidence for mini-rules comes from findings showing that lexically-specific rules are predominant at the earliest stages of language acquisition; see Braine (1976) and Maratsos (1979: 309 et passim) for early statements, Ninio (1999) and Tomasello (2000, 2003: pp. 117-121) for comprehensive reviews, and McClure et al. (2006) for a more recent review.

The transition from mini-rules to features and linking rules requires two additional steps, as shown in the following.

\section{Generalization}

Mini-rules are verb-specific, but they may be generalized to other verbs. The child's early verbs are predominantly activity verbs, and the lexical entries of most of these, include Cause and Control. Here I will describe schematically how the notions "cause"" and "control" develop and become associated with linking rules.

Suppose that a child has experienced the utterance Jane pushes the baby carriage and later on encounters the utterance Jimmy eats the cookie. In what way are these two sentences similar? The similarity the child fastens onto will not be that between Jimmy and Jane (perhaps Jimmy will be perceived to be more similar to some boy than to a girl like Jane). Nor are the activities referred to by the verbs push and eat very similar. Rather, the similarity is between two relations, namely, the relation between Jimmy and the activity of eating and that between Jane and the activity of pushing. Perceiving a similarity between the two events highlights the notions they have in common: Jane and Jimmy both initiate the activity i.e., partake of the notion "cause", and are in control of it. This similarity between the described events will be reinforced by similarity between the utterances expressing them: the words for Jane and Jimmy appear both in pre-verbal position. Since most activity verbs involve both causation and control, it is reasonable to assume that they constitute initially a single complex notion, and only when the child has to deal with verbs having only one of them, does differentiation set in.

Between any two situations there may be several relatively salient similarities. In the case of Jane's pushing and Jimmy's eating, for example, the child might note that both Jane and Jimmy hold something in their hands. Such similarities, call them "notions" if you will, will be short-lived, however. They

\footnotetext{
${ }^{28}$ The grammatical concept of subject is not a linguistic universal (Schachter \& Otanes, 1972; Evans \& Levinson, 2009) and so cannot be assumed to be available to the child. Linking has to be to surface properties like position in the sentence, or (in many languages) to a NP with an affix.
}

will not be frequently confirmed by additional utterances having similar structures, whereas the notions "cause" and "control" will be. Thus, when she encounters an utterance like Don is pushing Bill, Don may be holding nothing in his hands, but will be conceived of as causing the action and being in control. Incipient notions that have no function in the rule system of the language will soon be weeded out.

As the notions "cause" and "control" appear in association with additional verbs they become gradually more salient, and the tendency will be strengthened to generalize a mini-rule for one verb to other verbs associated with the same notions.

On the hypothesis that the child forms mini-rules and then generalizes them, one may expect her early rules to be restricted to narrow classes of semantically similar verbs. This is because the greater the similarity in meaning between any two verbs, the more likely is the mini-rule of one to generalize to the other. In fact, in the earliest stages of their linguistic development, children have often been found to deploy a rule for narrow categories of verbs, such as experiencer verbs or verbs of communication; see Braine (1976).

\section{Formation of Features}

As mentioned, notions are cognitive constructs and not semantic ones. In the mature linguistic system, linking rules are defined in terms of features, not of notions. Let us see now how a notion like "cause" crystallizes into the feature Cause.

A feature is:

a) a relatively well-delimited concept, and

b) accessed every time a given verb is used, irrespective of the situation it refers to.

Delimitation of features, a), is essentially a process of concept formation, like vocabulary acquisition. To learn the extension of $d o g$, the child will note similarities (of shape and behavior) between, say, the neighbor's dog and the family's poodle. But this is not sufficient: a sheep is also similar to the poodle, in some ways perhaps more so than the neighbor's dog. A linguistic factor clinches the matter: the child observes that the neighbor's dog is referred to by the word $d o g$, whereas a sheep is not. The linguistic factor that is common to verbs with a "causer", for instance, is the way they are realized in sentences by Feature linking rules. The child notes that sentences with internal causers are constructed in the same way as those with external ones, and thus forms the feature Cause. Similarly, the same Feature linking rules apply not only to verbs referring to changes of location (like fall) but also to changes of state (as in melt), and thus the feature Change is delimited ${ }^{29}$.

Independence of specific situations, b), will be attained by experience with the notion in question. For instance, the child will eventually find out that in referring to actions like coughing, one deploys the same linguistic structures even on occasions where the perpetrator apparently has no control over them.

In sum, features develop in the course of acquiring linking rules, and linking rules are formed on the basis of features; both are acquired concomitantly. The language learner "scrambles up an intellectual chimney, supporting himself against each side by pressures against the others", in Quine's (1960: p. 93) apt phrase.

The child at first uses mainly activity verbs, but she will hear

\footnotetext{
${ }^{29}$ Naturally, the child may for some time underextend a feature category or conflate it with another one (Cause with Attr-St, for instance), but eventually the Feature linking rules operating in adult language lead to her zeroing in on the adult categories.
} 
and produce some utterances with stative verbs, the subject participants of which have neither Cause nor Control, but rather Change or Attr-St. How can the language learner tell the various features apart? If all features were acquired simultaneously, this would be a serious problem, indeed. It appears, however, that features are acquired successively. In early stages of acquisition, the number of stative verbs (like want, sit and lie) is rather small compared to that of activity verbs. Presumably, the initial mini-rules for these verbs will be retained until the features Control and Cause have been fairly well established. Only when stative verbs have been acquired in greater numbers, will the feature Attr-St begin to be formed. As for Control and Cause, considering that most activity verbs involve both of them, these two features are presumably acquired simultaneously and constitute a single complex feature, which is bifurcated only much later, when the child has to deal with verbs having only Control or only Cause.

Acquisition of the feature Change proceeds essentially along the lines outlined for Attr-St. At the time Control and Cause are being formed, the child merely has mini-rules for verbs with the feature Change $e^{30}$. But this feature poses an additional problem, because it may be realized either as subject or as direct object. This is why the distinction between resulting and non-resulting features has been introduced. Acquiring this distinction should not pose any special difficulty, but possibly the child does not need any rules based on this distinction: she may circumvent it. She may learn a) the rather simple rule that a participant with Change does not qualify for subject position when another participant has Cause or Control, and b) the rules for a handful of verbs (such as lead, march and sleep) in an item-by-item manner. The only feature which apparently cannot be acquired by the abstraction process described in the foregoing is the negatively defined "default feature" $\varnothing$, but this does not impede acquisition, as will be shown in the next subsection.

Once features have been abstracted and the linking rules pertaining to them have been formed, they will readily be identified in subsequently learned verbs. Eventually there will be no longer any need to form mini-rules for new verbs. To learn how to construct a sentence with, say, touch, it is enough to learn the meaning of this verb, i.e., to know that this verb has two participants: the "toucher" and the "touchee" and that the "toucher" has the features Control and Cause. To say that $X$ touches $Y$, the child merely has to apply the previously acquired Feature linking rule so as to position the word or phrase for $X$ before touch. In comprehension, the Feature linking rule will be applied in reverse: If a NP is preverbal, then it may stand for the participant with Control (in this example: the "toucher", not the "touchee").

\section{Acquisition of Objects}

Some research on child language suggests that the child's first direct objects have the feature Change. Slobin (1979, quoted in Hopper and Thompson 1980) reports the case of a Russian speaking child who at first used the accusative suffix only for

\footnotetext{
${ }^{30}$ In a series of experimental tasks, Guberman (1992) found children's, and in some cases adults', performance with stative verbs to be poorer than with activity verbs. See also Gropen et al. (1991b) for an experimental study pertaining to the children's acquisition of the concept of change (their term is "object affectedness").

${ }^{31}$ But Ninio (1999: p. 647) found that the first verbs have only "low impact on their patients, such as change of possession".
}

verbs denoting "direct physical action on things", like give, carry, put, and throw, that is, for verbs with a Change object participant), and not for verbs like read or see $e^{31}$.

A limited linking rule to the effect that the participant with Change becomes a direct object in postverbal position may suffice for some time (because verbs like die and grow up, whose subjects have Change, presumably are not acquired in the earliest stages, and if they do, they will function only in minirules). At the two- and three-word stages, however, appear verbs like read, buy, ask, forget, love, and like with their direct objects (see, e.g., Braine, 1976: pp. 42-51; Tomasello, 1992: pp. 119-140, for English speaking; and Fortus, 1996: pp. 88-89, for Hebrew speaking children). The direct objects of these verbs do not refer to affected entities. They have the default feature $\varnothing$, and $\varnothing$ is the only feature that cannot be abstracted in the way described above.

There are two possible strategies for mastering the linking rules for direct objects:

a) The child forms a separate rule for each verb. For instance, she observes that when the verb want is used, the thing wanted is treated linguistically just like push and throw, verbs that involve affected entities. Such item-specific learning will have to be supplemented by the second strategy:

b) The child learns a negative rule (see sub-section on Semantics of the object category): The participant that lacks features linking it to the subject is realized as a direct object; the participant with the criterial features become subjects, and the other participant becomes the direct object (see Braine \& Hardy, 1982: p. 224, for a similar proposal).

It might be objected that well before there is evidence that they have mastered the subject-verb pattern many children use the verb-direct object pattern correctly (e.g., Tomasello, 1992). But no definite conclusion can be drawn from the child's verbal production, because she may be aware that an entity having Cause is involved in the situation she talks about and still fail to refer to that entity in her linguistic output. She may say, for instance, push ball without mentioning the agent of pushing (perhaps to save effort or because the identity of the agent is self-evident), but she will be aware that there is a "pusher"32. In this connection it is of interest that in some corpora, SVO precede VO constructions (Fortus, 1996; Keren-Portnoy in prep.).

An apparent difficulty with the above-mentioned strategy of learning a negative rule is that it assumes that the child can distinguish between direct and oblique objects. But this distinction may be acquired in stages. At an early stage of learning, oblique objects are presumably treated in the same way as direct objects. In fact, in many corpora of child language oblique objects appear without prepositions ${ }^{33}$. The question then becomes: How does the child move from this broad non-subject category to the mature direct object category?

As pointed out above, there is no sure-fire semantic criterion for the distinction between direct and oblique objects. It is plausible, though, that prepositions serve as a lever for narrowing down the non-subject category. Suppose the child repeatedly hears certain NPs preceded by the preposition from (e.g., take the milk from the refrigerator, pull it from the shelf) and notices

\footnotetext{
${ }^{32}$ Goldberg (2006) reports on a study of a child learning Russian who failed to pronounce a verb in her utterance, while having an implicit knowledge of it.

${ }^{33}$ Here are some examples culled from the CHILDES corpora: 1. Instrument without preposition: sweep broom, write pencil, eat hand. 2. Location without preposition: walking street, sitting chair, lie down stool.
} 
that from marks the expression standing for source of the motion. From the earlier non-subject category she thus separates out a new category, Source of motion, which has its own rules of realization. Later on, the same preposition, from, may appear with a somewhat different role, as in she got the book from her brother, and she forms an additional category. In this manner, non-subject NPs begin gradually to fall into classes according to the roles they play in the sentence (instrument, location, time, and so on), and Role linking rules are acquired.

\section{Acquisition of Thematic Roles and of Features Compared}

In the following, the acquisition theory outlined in the preceding is compared with accounts based on thematic roles.

\section{Features Simpler than Roles}

Intuitively, it should be easier to attend to semantic features than to the more global thematic roles. Discussing the advantage of his "entailments" over thematic roles, Dowty observes.

It is certainly not obvious that in ordinary reasoning and conversation people directly pay attention to or worry about whether something really was or was not a Theme or a Source or an Agent (in some sense of Theme, etc.); but we do concern ourselves all the time, both in everyday life and in courts of law, and sometimes to a painstaking degree, with whether an act was really volitional or not, whether something really caused something or not, ... whether something was moving or stationary, whether something changed in a certain way or not... (Dowty, 1991: p. 575).

\section{Acquiring Thematic Hierarchies}

Suppose that, contrary to the present theory, the selection of subject and direct object is based on thematic roles. These would have to be formed, like features, in the course of the child's cognitive development. Concepts such as Agent and Patient do not come ready-made. They start out as cognitive notions that must be crystallized into well-delineated concepts, if they are to be deployed in the child's linguistic system. In this respect, a system based on features seems to have an advantage, since the number of features is much smaller than that of thematic roles.

Furthermore, according to current theories, subject and object selection are based on a thematic hierarchy. Acquiring such a hierarchy would be a much more arduous task than learning the Feature linking rule in 28). The child is never exposed to such a hierarchy in its entirety, and so would have to piece it together by means of pairwise comparisons. Authors are not agreed on the number of roles in a hierarchy, which may be up to 10 or 15 (Baker, 1997: pp. 107-108), and even on the unrealistic assumption that the child makes maximum use of transitivity (if $\mathrm{X}$ comes before $\mathrm{Y}$ and $\mathrm{Y}$ before $\mathrm{Z}$, then $\mathrm{X}$ comes before $Z$ ), mastering the hierarchy would require a large number of comparisons to be made. For instance, Jackendoff's (1990b: pp. 259-260) list of roles for transitive verbs would require 18 such comparisons (e.g., Theme precedes Location, etc.) ${ }^{34}$. By contrast, mastering the simple linking rules is a much less arduous task than learning a thematic role hierarchy would be. It is also simpler than counting (and perhaps assigning weights to) Dowty's (1991) “entailments".

Another advantage of accounting for subject and object selection in terms of features is that it provides a simpler solution to the problem of the many-to-many relation between semantic and syntactic concepts. Here I will go into this at some length.

\section{Semantic-Syntactic Mapping-A Previous Account}

In the early 1970 s, it was proposed that what the child learns is how language expresses semantic relations like Agent and Patient, i.e., thematic roles (e.g., Bowerman, 1973; Schlesinger, 1971; see also Slobin, 1970). An objection that was advanced against this so-called "semantic approach" from very early on was that such thematic roles are not congruent with formal syntactic ones. An Agent can be not only the sentence subject, but also a NP in a by-phrase (in a passive sentence) or in a withphrase (I swept the room with Denis), and conversely, subjects can be not only Agents, but also Patients (the subjects of many passive sentences), Themes (London Bridge is falling down), Experiencers (Celia admires Doris), Natural Forces (The storm devastated the village), and Instruments (The new blower dried her hair fast). Likewise, there are direct objects that are not Patients, and conversely, not all Patients are direct objects.

At the time this objection began to be voiced, the concept of a thematic hierarchy was already taking shape (Fillmore, 1968), albeit not under this name. But the language acquisition literature did not resort to it in dealing with this objection, perhaps because it was felt that mastering a system of precedence relations would be too arduous a task for the young child to tackle. Instead, a different solution began to be developed: Subjects and direct objects that are not Agents or Patients, it was argued, are absorbed into these semantic categories. Referents of certain verbs may be conceived of by the child as somehow related to those denoting straightforward activities carried out by agents. Schlesinger (e.g., 1974, 1988) proposed that the extension of semantic categories proceeds on the basis of semantic as well as of formal similarity. This process, which was dubbed semantic assimilation, would lead to a gradual expansion of the original agent category, so as to include experiencers (Schlesinger, 1992) and instruments (Schlesinger, 1989), until it coincides with the mature subject category. Similarly, Maratsos (1981) and Tomasello (2000) have argued that semantic categories may be extended so as to comprise atypical instances.

Here are some factors that might account for the semantic assimilation of subjects that are not, strictly speaking, Agents (Schlesinger, 1988):

a) Similarity:

The child who hears an utterance like 51a) may conceive of the bridge as moving across the river just as a person walking across it would be. 51b) is another example of metaphorical extension, or of "fictive action", as MacWhinney (1999: p. 231) calls it: the shelf is anthropomorphized and viewed as "holding" objects, just as a human would.

51) a. The bridge crosses the river.

b. This shelf holds twenty books.

b) Contrast:

52) a. Herb is lying on the couch.

b. Herb is standing in the doorway.

Lying is not an activity, and Herb cannot properly be regarded as an Agent in the full sense of the term. The same may be said of standing, which does not necessarily involve a typical Agent. However, lying and standing are treated as Agents because they contrast with verbs of bodily movement, such as

\footnotetext{
${ }^{34}$ If a hierarchy were to contain a much smaller number of thematic roles, each role would tend to be more comprehensive, and the child would face the problem of forming a more general, i.e., abstract, concept.
} 
walking and running. Similarly, falling may be regarded in contrast to jumping or walking, and therefore when a person who is asserted to have fallen is referred to by a word in subject position, he is conceived of as an Agent. Eventually, not only falling people, but also falling objects will be regarded as Agents due to the similarity factor, a).

c) Embeddedness in activity:

53) a. Ronald is sleeping in his armchair.

b. Ronald is waiting for his sister.

The verb sleep will be heard by the child in situations in which various activities are going on: lying down, closing one's eyes, turning round in bed, etc. Formal similarity will also be a factor here (as in semantic assimilation generally): The child notes that the word referring to the sleeper is in pre-verbal position, and thus comes to regard the sleeper as an Agent. Similarly, waiting is normally accompanied by activities like walking up and down, making inquiries, and the like, so that 53b) is conceived of as part of a scene where Ronald is active as an Agent.

In this manner, so the semantic assimilation hypothesis went, subjects that are not literally speaking Agents, come to be regarded as Agents and expressed linguistically like them. It has to be admitted that in some instances the proposed explanations, while plausible, are rather ad hoc. See also Bowerman (1974) for critical comments on the semantic assimilation hypothesis.

A later finding by Bowerman (1990) is also difficult to reconcile with the claim that semantic categories are gradually extended to accommodate non-typical instances. Bowerman argues as follows. If thematic roles like Agent and Patient are extended in the course of acquisition, one would expect "real", unextended Agents and Patients to be acquired before extended ones. But she found that her two daughters made no fewer errors of word order in their sentences with prototypical Agents and Patients than in those with non-prototypical Agents and Patients ${ }^{35}$.

Let us see now how the mismatch between semantic and syntactic categories can be accounted for by a theory based on semantic features.

\section{Semantic-Syntactic Mapping-A Feature Based Account}

The problem the semantic assimilation hypothesis was designed to account for was that semantic categories and syntactic ones stand in a many-to-many relation. According to the present theory, subject selection is based on the presence of one or more of four features. But these features may appear also in subjects that are not typical agents (as in examples 2) - 5)). Let us see now in some detail how this works out.

In 52), Herb matches perfectly the subject participants of lie and stand, which have Cause, Control, and Attr-St; see 6). Ronald in 53) matches the subject participants of sleep and wait in respect to Control (and arguably also in respect to Attr-St). In the case of 51), the present account converges on the one given by the semantic assimilation hypothesis: As pointed out above, matching does not require the referent of the NP to have properties corresponding to all the features in the participant in the lexical entry, but only a general similarity in meaning between the NP and the participant. In 51a), the mental representation of the bridge corresponds with that of the subject participant in the lexical entry of cross, because a bridge can be imagined as

\footnotetext{
${ }^{35}$ Bowerman's study was intended to test Pinker's $(1984,1989)$ hypothesis that these roles are innate.
}

crossing a river just as a boat or a swimmer may do. In the same way, this shelf in 51b) matches with the subject participant of hold.

Bowerman's (1990) findings, alluded to above, do not conflict with feature theory, because our features have a wider applicability than Agent and Patient roles. Among the verbs classified by Bowerman as taking non-prototypical roles are draw, write, look, talk, cook, ride, and play, and all these verbs have subject participants with the features Cause and Control.

\section{Summary}

Linking rules for subject and direct object selection have been formulated in terms of a set of four semantic features, and the distinction between resulting and non-resulting features. Unlike thematic roles, semantic features are not ascribed to NPs in sentences but to participants in lexical entries. The assumption made here is that the lexical entry of a verb contains either one or two participants with features. Thematic roles are involved only in linking rules for other syntactic functions, notably oblique objects. The theory can account for phenomena that are difficult to explain in terms of thematic roles and of proto-roles. In this paper, it has been worked out for subjects and objects in simple sentences in English, and it is shown how it affords a viable theory of native language acquisition. It remains to be seen whether additional semantic features are required for the explanation of other linguistic regularities and for other languages.

\section{Acknowledgements}

I am very grateful to Moshe Anisfeld, Ainat Guberman, Tamar Keren-Portnoy, Yonata Levy, Michael Maratsos, Anita Mittwoch, Anat Ninio, Dan Slobin, and Virve Vihman for important comments on a draft of this paper. Thanks also to Shlomo Danziger for the care taken in preparing the manuscript for publication.

\section{REFERENCES}

Anderson, S. R. (1971). On the role of deep structure in semantic interpretation. Foundations of Language, 7, 387-396.

Andrews, A. D. (2007). The major functions of the noun phrase. In T. Shopen (Ed.), Language typology and syntactic description (pp. 64154). Cambridge: Cambridge University Press.

Baker, M. C. (1988). Incorporation: A theory of grammatical function changing. Chicago, IL: University of Chicago Press.

Baker, M. C. (1997). Thematic roles and syntactic structure. In L. Haegeman (Ed.), Elements of grammar: Handbook in generative syntax (pp. 72-137). Dordrecht: Kluwer. doi:10.1007/978-94-011-5420-8 2

Beavers, J. T. (2006). Argument/oblique alternations and the structure of lexical meaning. Stanford, CA: Stanford University dissertation.

Belletti, A., \& Rizzi, L. (1988). Psych-verbs and $\theta$ theory. Natural Language and Linguistic Theory, 6, 291-352. doi:10.1007/BF00133902

Bowerman, M. (1973). Early syntactic development. Cambridge: Cambridge University Press.

Bowerman, M. F. (1974). Discussion summary-Development of concepts underlying language. In R. L. Schiefelbusch, \& L. L. Lloyd (Eds.), Language perspectives-Acquisition, retardation, and intervention (pp. 191-209). Baltimore, MD: University Park Press.

Bowerman, M. (1990). Mapping thematic roles onto syntactic functions: Are children helped by innate linking rules? Linguistics, 28, 1253 1289. doi:10.1515/ling.1990.28.6.1253

Bowerman, M., \& Croft, W. (2008). The acquisition of the English causative alternation. In M. Bowerman, \& P. Brown (Eds.), Cross- 


\section{M. SCHLESINGER}

linguistic perspectives on argument structure (pp. 279-307). New York, NY: Lawrence Erlbaum Associates.

Braine, M. D. S. (1976). Children's first word combinations. Monographs of the Society for Research in Child Development 41 (1, Serial No. 164). doi:10.2307/1165959

Braine, M. D. S., \& Hardy, J. A. (1982). On what cases there are, why they are, and how they develop: An amalgam of a priori considerations, speculation, and evidence from children. In E. Wanner, \& L. Gleitman (Eds.), Language acquisition: The state of the art (pp. 219239). Cambridge: Cambridge University Press.

Chomsky, N. (1982). The generative enterprise: A discussion with Riny Huybregts and Henk van Riemsdijk. Dordrecht: Foris.

Chomsky, N. (1995). The minimalist program. Cambridge, MA: MIT Press.

Davis, A. R. (2001). Linking by types in the hierarchical lexicon. Stanford, CA: CSLI Publications.

Davis, A. R., \& Koenig, J.-P. (2000). Linking as constraints on word classes in a hierarchical lexicon. Language, 76, 56-91.

Dowty, D. (1989). On the semantic content of the notion of "thematic role". In G. Chiercha, B. H. Partee, \& R. Turner (Eds.), Properties, types and meaning (pp. 69-129). Dordrecht: Kluwer. doi:10.1007/978-94-009-2723-0_3

Dowty, D. (1991). Thematic proto-roles and argument selection. Language, 67, 547-619.

Evans, N., \& Levinson, S. C. (2009). The myth of language universals: Language diversity and its importance for cognitive science. Behavioral and Brain Sciences, 32, 429-492. doi:10.1017/S0140525X0999094X

Fillmore, C. J. (1968). The case for case. In E. Bach, \& R. T. Harms (Eds.), Universals in linguistic theory (pp. 1-88). New York, NY: Holt, Rinehart, and Winston.

Fillmore, C. (1970). The grammar of hitting and breaking. In R. A. Jacobs, \& P. A. Rosenbaum (Eds.), Readings in English transformational grammar (pp. 120-133). Waltham, MA: Ginn.

Fillmore, C. J. (2003). Form and meaning in language, vol. 1. Stanford, CA: Center for the Study of Language and Information.

Fortus, R. (1996). Semantic relations in the acquisition of language: An analysis of one child's first word combinations. MA Thesis, Jerusalem: Hebrew University of Jerusalem.

Gelman, S. A., \& Opfer, J. E. (2002). Development of the animateinanimate distinction. In U. Goswami (Ed.), Handbook of childhood cognitive development (pp. 151-166). Malden, MA: Blackwell doi:10.1002/9780470996652.ch7

Gleitman, L. R., Gleitman, H., Miller, C., \& Ostrin, R. (1996). Similar, and similar concepts. Cognition, 58, 321-376.

doi:10.1016/0010-0277(95)00686-9

Goldberg, A. E. (2006). Constructions at work: The nature of generalization in language. New York, NY: Oxford University Press.

Grimshaw, J. (1990). Argument structure. Cambridge, MA: MIT Press.

Gropen, J., Pinker, S., Hollander, M., Goldberg, R., \& Wilson, R. (1989). The learnability and acquisition of the dative alternation in English. Language, 65, 203-257. doi:10.2307/415332

Gropen, J., Pinker, S., Hollander, M., \& Goldberg, R. (1991a). Affectedness and direct objects: The role of lexical semantics in the acquisition of verb argument structure. Cognition, 41, 153-195. doi:10.1016/0010-0277(91)90035-3

Gropen, J., Pinker, S., Hollander, M., \& Goldberg, R. (1991b). Syntax and semantics in the acquisition of locative verbs. Journal of Child Language, 18, 115-151. doi:10.1017/S0305000900013325

Guberman, A. (1992). The development of the verb category in the Hebrew child language. Ph.D. Thesis, Jerusalem: Hebrew University.

Hoekstra, T. (1992). Aspect and Theta Theory. In I. M. Roca (Ed.), Thematic structure: Its role in grammar (pp. 145-174). Berlin: Foris. doi: $10.1515 / 9783110872613.145$

Hopper, P. J., \& Thompson. S. A. (1980). Transitivity in grammar and discourse. Language, 56, 251-299.

Hudson, R. (1992). So-called "double objects" and grammatical relations. Language, 68, 251-276. doi:10.2307/416941

Jackendoff, R. (1987). The status of thematic relations in linguistic theory. Linguistic Inquiry, 18, 369-411.

Jackendoff, R. (1990a). On Larson's treatment of the double object construction. Linguistic Inquiry, 21, 427-456.

Jackendoff, R. (1990b). Semantic structures. Cambridge, MA: MIT Press.

Jespersen, O. (1933). Essentials of English grammar. London: Allen \& Unwin.

Kako, E. (2006). Thematic role properties of subjects and objects. Cognition, 101, 1-42. doi:10.1016/j.cognition.2005.08.002

Kasof, J., \& Lee, J. Y. (1993). Implicit causality as implicit salience. Journal of Personality and Social Psychology, 65, 877-892. doi:10.1037/0022-3514.65.5.877

Keren-Portnoy, T. (In preparation). Long is easy, short is hard.

Kiparsky, P. (2001). Structural case in Finnish. Lingua, 111, 315-376. doi:10.1016/S0024-3841(00)00035-8

Leslie, A. M., \& Keeble, S. (1987). Do six-month old infants perceive causality? Cognition, 25, 265-288. doi:10.1016/S0010-0277(87)80006-9

Levin, B. (1993). English verb classes and alternations: A preliminary investigation. Chicago, IL: University of Chicago Press.

Levin, B., \& Rappaport Hovav, M. (1995). Unaccusativity: At the syntax-lexical semantics interface. Cambridge, MA: MIT Press.

Levin, B., \& Rappaport Hovav, M. (2005). Argument realization. Cambridge: Cambridge University Press. doi:10.1017/CBO9780511610479

MacWhinney, B. (1999). The emergence of language from embodiment. In B. MacWhinney (Ed.), The emergence of language (pp. 213-256). Mahwah, NJ: Lawrence Erlbaum.

Maratsos, M. P. (1979). How to get from words to sentences. In D. Aronson, \& R. W. Rieber (Eds.), Psycholinguistic research: Implications and applications (pp. 285-356). Hillsdale, NJ: Lawrence Erlbaum.

Maratsos, M. (1981). Problems in categorial evolution: Can formal categories arise from semantic ones? In W. Deutsch (Ed.), The child's construction of language (pp. 245-261). London: Academic Press.

McClure, K., Pine, J. M., \& Lieven, E. V. M. (2006). Investigating the abstractness of children's early knowledge of argument structure. Journal of Child Language, 23, 693-720. doi:10.1017/S0305000906007525

McRae, K., Todd, R., Ferreti, T. R., \& Amyote, L. (1997). Thematic roles as verb-specific concepts. Language and Cognitive Processes, 12, 137-176. doi:10.1080/016909697386835

Newmeyer, F. J. (2002). Optimality and functionality: A critique of functionally-based optimality-theoretical syntax. Natural Language and Linguistic Theory, 20, 43-80. doi:10.1023/A:1014290005775

Ninio, A. (1999). Pathbreaking verbs in syntactic development and the question of prototypical transitivity. Journal of Child Language, 26, 619-653. doi:10.1017/S0305000999003931

Ninio, A. (2006). Language learning and the learning curve. Oxford: Oxford University Press. doi:10.1093/acprof:oso/9780199299829.001.0001

Pinker, S. (1984). Language learnability and language development. Cambridge, MA: Harvard University Press.

Pinker, S. (1989). Learnability and cognition: The acquisition of argument structure. Cambridge, MA: MIT Press.

Premack, D. (1990). The infant's theory of self-propelled objects. Cognition, 36, 1-16. doi:10.1016/0010-0277(90)90051-K

Quine, W. Van O. (1960). Word and object. Cambridge, MA: MIT Press.

Rappaport, M., \& Levin, B. (1988). What to do with $\theta$-roles. In W. Wilkins (Ed.), Syntax and semantics, vol. 21: Thematic relations (pp. 7-36). San Diego: Academic Press.

Rappaport Hovav, M., \& Beth Levin, B. (2008). The English dative alternation: The case for verb sensitivity. Journal of Linguistics, 44, 129-167. doi:10.1017/S0022226707004975

Rozwadowska, B. (1988). Thematic restrictions on derived nominals. In W. Wilkins (Ed.), Syntax and semantics, vol. 21: Thematic relations (pp. 147-165). San Diego: Academic Press.

Rosta, A. (2002). Review of the book cognitive space and linguistic case, by Izchak M. Schlesinger. Journal of Pragmatics, 34, 69-78. doi:10.1016/S0378-2166(01)00013-3

Schachter, P., \& Otanes, F. T. (1972). Tagalog reference grammar. 


\section{M. SCHLESINGER}

Berkeley: University of California Press.

Schlesinger, I. M. (1971). Production of utterances and language acquisition. In D. I. Slobin (Ed.), The ontogenesis of grammar (pp. 63-101). New York: Academic Press.

Schlesinger, I. M. (1974). Relational concepts underlying language. In R. L. Schiefelbusch, \& L. L. Lloyd (Eds.), Language perspectivesacquisition, retardation and intervention (pp. 129-151). Baltimore, MD: University Park Press.

Schlesinger, I. M. (1977). Production and comprehension of utterances. Hillsdale, NJ: Lawrence Erlbaum Associates.

Schlesinger, I. M. (1988). The origin of relational categories. In Y. Levy, I. M. Schlesinger, \& M. D. S. Braine (Eds.), Categories and processes in language acquisition (pp. 121-178). Hillsdale, NJ: Lawrence Erlbaum.

Schlesinger, I. M. (1989). Instruments as agents: On the nature of semantic relations. Journal of Linguistics, 25, 189-210. doi: $10.1017 / \mathrm{S} 0022226700012147$

Schlesinger, I. M. (1992). The experiencer as an agent. Journal of Memory and Language, 31, 315-332. doi:10.1016/0749-596X(92)90016-Q

Schlesinger, I. M. (1995). Cognitive space and linguistic case: Semantic and syntactic categories in English. Cambridge: Cambridge University Press. doi:10.1017/CBO9780511551321

Shibatani, M. (1996). Applicatives and benefactives: A cognitive account. In M. Shibatani, \& S. A. Thompson (Eds.), Grammatical constructions: Their form and meaning (pp. 157-194). Oxford: Clarendon Press.

Siewierska, A. (1991). Functional grammar. London: Routledge.

Slobin, D. (1970). Universals of grammatical development in children. In G. B. Flores D’Arcais, \& W. J. M. Levelt (Eds.), Advances in psycholinguistics (pp. 174-186). Amsterdam: North Holland.

Slobin, D. (1979). The role of language in language acquisition. Invited address to the 50th Annual Meeting of the Eastern Psychological Association, Philadelphia. Unpublished ms., Berkeley, CA: University of California.

Tomasello, M. (1992). First verbs: A case study of early grammatical development. New York: Cambridge University Press. doi:10.1017/CBO9780511527678

Tomasello, M. (2000). Do young children have adult syntactic competence? Cognition, 74, 209-253. doi:10.1016/S0010-0277(99)00069-4

Tomasello, M. (2003). Constructing a language. Cambridge, MA: Harvard University Press.

Tversky, A. (1977). Features of similarity. Psychological Review, 84, 327-352. doi:10.1037/0033-295X.84.4.327

Van Valin Jr., R. D. (2005). Exploring the syntax-semantic interface. Cambridge: Cambridge University Press. doi:10.1017/CBO9780511610578

Van Valin Jr., R. D., \& Wilkins, D. P. (1996). The case for 'Effector': Case roles, agents, and agency revisited. In M. Shibatani, \& S. A. Thompson (Eds.), Grammatical constructions: Their form and meaning (pp. 289-322). Oxford: Clarendon Press.

Wilkins, W. (1988). Thematic structure and reflexivization. In W. Wilkins (Ed.), Syntax and semantics, Vol. 21: Thematic relations (pp. 191-213). San Diego: Academic Press.

Witman, S. (2000). Mussa'im yeshirim va'akifim betsarfatit, ivrit ve'anglit: Mehkar hashva'ati [Direct and oblique objects in French, Hebrew, and English: A comparative study]. Unpublished paper, Jerusalem: Hebrew University of Jerusalem.

Zubizaretta, M. L. (1987). Levels of representation in the lexicon and in the syntax. Dordrecht: Foris. 